\title{
Article \\ A 3D Printed Physical Human-Robot Interface Based on a Sizing System to Facilitate Customization: Wearable Robots for Paraplegia
}

\author{
Chil-Yong Kwon ${ }^{1, *}$, Jung-Sik Jang ${ }^{1}\left(\mathbb{D}\right.$ and Gyoo-Suk Kim ${ }^{2}$ \\ 1 Department of Product Innovation Design, Graduate School of Techno-Design, Kookmin University, \\ Seoul 02707, Korea; kmjanggo@kookmin.ac.kr \\ 2 Rehabilitation Engineering Research Institute, Incheon 21419, Korea; gskim7379@kcomwel.or.kr \\ * Correspondence: dragonkk@kcomwel.or.kr; Tel.: +82-01-2522-3702
}

Citation: Kwon, C.-Y.; Jang, J.-S.; Kim, G.-S. A 3D Printed Physical Human-Robot Interface Based on a Sizing System to Facilitate Customization: Wearable Robots for Paraplegia. Appl. Sci. 2021, 11, 5143. https://doi.org/10.3390/app11115143

Academic Editor: Alessandro Di Nuovo

Received: 5 May 2021

Accepted: 30 May 2021

Published: 1 June 2021

Publisher's Note: MDPI stays neutral with regard to jurisdictional claims in published maps and institutional affiliations.

Copyright: () 2021 by the authors. Licensee MDPI, Basel, Switzerland. This article is an open access article distributed under the terms and conditions of the Creative Commons Attribution (CC BY) license (https:// creativecommons.org/licenses/by/ $4.0 /)$.

\begin{abstract}
Wearable robots that assist paraplegia patients should be manufactured according to the shape of the individual wearer. With the development of advanced three-dimensional (3D) printing technologies, such customizations are becoming available. However, conventional 3D printing customization requires extensive template remodeling, which is non-productive and inefficient. This study proposes a 3D-printed (3DP) physical human-robot interface (pHRI) based on a sizing system that facilitates customization to body shapes. The proposed system is a pre-developed pHRI in various sizes and shapes using a human body shape database. Conformity of shapes and dimensions were evaluated visually via shape deviation analysis for 10 persons having paraplegia. With the proposed 3DP-pHRI, the trunk comprised 18 sections and the shank comprised nine. A biased trend of coverage rates in the shank 3DP-pHRI size system was identified. The trunk and shank subsystems were found to be adequate in terms of shapes and dimensions, with values within the mean deviation range of $\pm 10 \mathrm{~mm}$. A novel 3DP-pHRI size system facilitating customization tool for fabricating wearable robots for paraplegia patients according to body shape was developed, and its effectiveness was assured. The new system can be used for various wearable robot pHRIs, and the database is expected to supply a comprehensive pHRI template library.
\end{abstract}

Keywords: 3D printing; customization; paraplegia; physical human-robot interface; sizing system; wearable robot

\section{Introduction}

Research activities in the field of wearable robots have expanded rapidly over the past 10 years, providing remarkable advancements for rehabilitative medicine, assistive living, and similar industries [1]. For people suffering paraplegia caused by spinal-cord injury (SCI), gait training using a wearable robot goes beyond simple walking rehabilitation. It has additional therapeutic effects, such as improving blood circulation, increasing bone density, and easing digestive function [2]. It is also known to significantly lower mortality and improve life expectancy [3]. In the field of rehabilitative medicine, studies have been actively conducted to evaluate the safety, efficacy, and benefits of wearable robot technology for such patients [4-7]. Most research has focused on improvements to machine performance [8]. Although the wearability of such devices is an important factor, developments have not considered this aspect from the user perspective [9]. Moreover, the physical human-robot interface (pHRI) for the wearable robot appliance has been overlooked in related studies [10].

A wearable robot comprises a driving unit, an exoskeleton frame, and a pHRI that connects the human body and the robot. The force generated by the driving unit is transmitted to the pHRI, dispersed through the part contacting the human body, and transmitted to the body [11]. The gait-assistance performance of a wearable robot depends 
on how effectively the force generated by the robot is transmitted in this fashion [12]. A recent study reported that a force transmission loss of up to $50 \%$ can occur, owing to the relative movement between the wearable robot and the human body, which is exacerbated by improper customization [13]. From a biomechanical perspective, the lower extremities must have enough strength to support the body weight [14]. Accordingly, in addition to the local dysfunction of the parts in question, problems occurring in the lower extremities may lead to other problems that negatively affect the upper body (e.g., pelvis and spine). Considering the biomechanical mechanism of the lower extremities and the potential loss of force generated by the robot driving unit during transmission, the pHRI should be configured to ensure integrated connectivity between the human body and the wearable robot to ensure appropriate contact area for improved comfort and safety [15]. Because people with paraplegia are more susceptible to skin lesions and bedsores, this interaction is a crucial factor [16]. Excessive pressure from pHRI can lead to skin ulcers [17], and improper physical contact often causes pain and discomfort $[18,19]$. Therefore, it is important to maintain a safe contact pressure applied to the human body via the pHRI so that damage and discomfort can be minimized [20].

Based on this information, it is clear that a wearable robot for people with paraplegia should be manufactured according to the shape of the body of the individual wearer. When examining extant pHRI applications, there have been cases where off-the-shelf orthopedic pHRIs were applied to reduce costs [21-23]. However, most were indeed custom-made [10]. The most traditional customization methods have been manually intensive, and include plaster casting and polyurethane foaming. Recently, with the development of three-dimensional (3D) printing manufacturing technology, a new method of customization based on body shape has been introduced. However, such approaches involve direct modeling, which is quite laborious. Direct-modeling customization requires remodeling the baseline template according to the shape of the 3D-scanned body surface, which exhibits low productivity and poor efficiency across multiple patients. In this respect, to increase the usefulness of customization to the body shape via 3D printing, a new method is needed to realize customization without template remodeling.

Therefore, this study proposes a new 3DP pHRI based on a sizing system to facilitate customization via $3 \mathrm{D}$ printing. To verify its effectiveness, the conformity of shape and dimension is evaluated. The proposed size-system-based 3DP-pHRI leverages a predeveloped (libraryized) pHRI comprising various sizes and shapes based on a human body shape database.

\section{Materials and Methods}

This study was conducted based on the hypothesis that conformity of shape and dimensions can be realized by selecting a 3DP-pHRI sizing system that best matches the body shape of the wearer, manufacturing it using 3D printing, and assembling it using a wearable robot. To test this hypothesis, a three-stage research plan was established. In Stage 1, a sizing system for the 3DP-pHRI was designed. In Stage 2, the shape-pattern design of the 3DP-pHRI template was developed. In Stage 3, clinical evaluation took place. This study specifically focuses on Step 1 . The remainder will be covered in future research.

Considering the configuration of the selected wearable robot, a sizing system was built for the trunk and shank parts of the human body. A body shape database of people without disabilities was used for the development of this sizing system, owing to the practical difficulty of obtaining body-shape data from people with paraplegia. Regarding system development, a sizing system for the 3DP-pHRI was developed through segmenting sizing sections and generating an average human body model for each section. For the evaluation of the conformity of dimensions, the developed system employed 3DP manufacturing, and visual observations and shape deviation analyses were conducted for 10 persons with paraplegia to examine the effectiveness of body-shape customization. 


\subsection{Configuration of the Wearable Robot}

The wearable robot selected for the study switches from reciprocating gait orthosis (RGOs) to power gait orthosis (PGOs) according to the gait-training stage of physical therapy. It comprises body fixation and driving modules. The body fixation module consists of a trunk module that fixes the waist of the wearer in place and supports the spine, a thigh fixation module that is worn on the thigh, and a shank fixation module that is worn on the calf. The driving module is composed of hip- and knee-joint driving units to generate forces in the joints to induce walking movements. RGOs can be switched to PGOs by selectively combining and using the joint driving units of the driving module. To apply the hip-joint driving unit, it is superimposed on the hip-joint frame, and to apply the knee-joint driving unit, the manual knee joint is replaced with the driving unit. The overall composition of the wearable robot is shown in Figure 1.

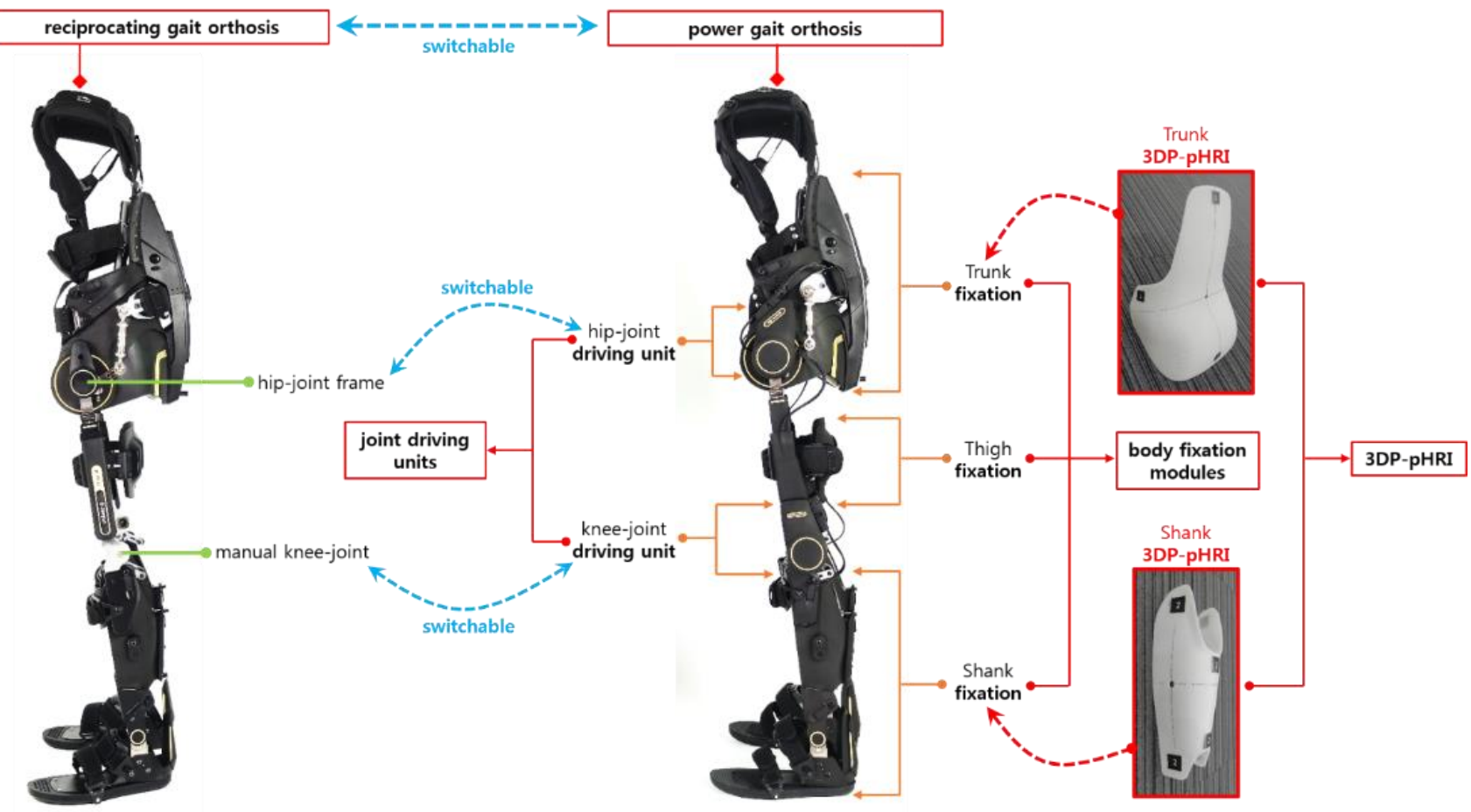

Figure 1. Hardware configuration of the wearable robot.

\subsection{Analysis of Sizing System Generation Method}

With reference to previous studies related to size-system generation [24-36], applicable techniques and sample data for segmenting body sections and creating an average human body model were analyzed. Table 1 shows the results.

Table 1. Analysis of size-system generation method.

\begin{tabular}{|c|c|c|c|}
\hline \multicolumn{2}{|c|}{ Division } & Applicable Technique & Sample Data Type \\
\hline $\begin{array}{l}\text { Size-section } \\
\text { Segmentation }\end{array}$ & & $\begin{array}{c}\text { Grid method } \\
\text { Clustering method } \\
\text { Optimization method }\end{array}$ & $\begin{array}{c}\text { 2D } \\
\text { Human body } \\
\text { measurement data }\end{array}$ \\
\hline \multirow{3}{*}{$\begin{array}{c}\text { Average } \\
\text { Human model } \\
\text { generation }\end{array}$} & \multirow{2}{*}{$\begin{array}{l}\text { Modeling method } \\
\text { utilization }\end{array}$} & $\begin{array}{l}\text { Wireframe } \\
\text { modeling }\end{array}$ & \multirow{2}{*}{$\begin{array}{c}\text { 3D } \\
\text { Human body } \\
\text { shape-model data }\end{array}$} \\
\hline & & $\begin{array}{l}\text { Morphing } \\
\text { modeling }\end{array}$ & \\
\hline & Database utilization & Template model fitting & $\begin{array}{c}\text { Scan-template } \\
\text { model-pair database }\end{array}$ \\
\hline
\end{tabular}


Statistical analysis techniques (e.g., the Grid method) are mainly used for segmenting sizing sections, and two-dimensional (2D) human body measurement data are used as sample data. The segmentation of the size section is based on the total coverage rate (e.g., 95\%) and the minimum coverage rate (e.g., $2 \%$ ) throughout the human body dimension database, forming a grid in the order of relatively high coverage rates until the specified coverage rate is satisfied. The segmentation of the size section can be approached in three ways: the grid method, the clustering method, and the optimization method, according to the method of determining the grid $[27,33]$. The grid method generates several standardized grids to satisfy the specified total coverage rate (e.g., $95 \%$ ) based on important variables [34]. The clustering method determines the appropriate number of clusters by analyzing the decreasing trend in the average distance between objects belonging to the cluster according to the change in the number of clusters (e.g., 2 to 50) [35]. The optimization method is a section segmentation method that minimizes total loss while maximizing target acceptance rate by using a loss function and an optimization algorithm [36]. Among the three methods, the grid method, which is most commonly used in the anthropometry field, was used as a method for subdividing the size section.

Regarding the modeling techniques applicable to provide average human body model generation, wireframe modeling and morphing are generally used, and 3D human body shape model data are used as sample data. When using a database for average human body model generation, the template model-fitting technique is the most common, and the scan model database, including feature information, is used for sample data. According to a previous study [24], wireframe modeling is advantageous for various averaging practices that require high precision, and body section modeling using a human body model is performed to complement the missing body shape information between the sections of the wireframe. According to other studies [25,26], morph modeling is advantageous for rapid averaging techniques that do not require high precision, but it requires controlling noise factors, such as polygon-count adjustments and shape removal, to ensure reliability. According to additional studies [29-32], the template model-fitting technique generates an average model by matching the topology of 3D human body shape models, and it requires a database of pre-fitted scan-template model pairs. In this study, among the three approaches for average human body model generation, wireframe modeling, which is advantageous for precise averaging, was selected.

\subsection{Sizing System Development}

To develop a sizing system, the process of segmenting size sections using the grid method and generating an average human body model using the wireframe modeling technique for each section was planned. For segmenting the size sections, a development process was planned to select important variables based on methods presented in the literature $[24,27,28]$ and to form a representative grid through cross analysis between the important variables. Table 2 shows the planned process of size-section segmentation.

For generating the average body model for each section, a development process was planned to select the 3D sample model for each size section based on the method presented in the study of [24] and to analyze the cross-section of the selected sample models to generate the average wireframe. Table 3 shows the planned process of average model generation. 
Table 2. Size-section segmentation process.

\begin{tabular}{cc}
\hline Step & Content \\
\hline 1. Obtaining sample data & 2D human body measurement data are used. \\
\hline 2. Selecting important variables & $\begin{array}{c}\text { Three body measurements for body shape classification are selected as } \\
\text { the important variables. }\end{array}$ \\
\hline 3. Segmenting important variables into section & $\begin{array}{c}\text { Important variables are segmented into section through a descriptive } \\
\text { statistical analysis. }\end{array}$ \\
\hline 4. Primary cross-tabulation analysis & $\begin{array}{c}\text { Primary size sections are generated based on the important variables 1 } \\
\text { and 2. }\end{array}$ \\
\hline 5. Secondary cross-tabulation analysis & $\begin{array}{c}\text { Final size sections are generated by applying the important variable 3 to } \\
\text { the primary size sections. }\end{array}$ \\
\hline 6. Forming the representative grid & $\begin{array}{c}\text { Representative grid for each section is formed after generating the } \\
\text { sample data into a 3D scatterplot. }\end{array}$ \\
\hline 7. Generating size of important variables for each representative grid & Mean value of each important variable of the sample data included in \\
each representative grid is calculated.
\end{tabular}

Table 3. Average model generation process.

\begin{tabular}{cr}
\hline \multicolumn{1}{c}{ Step } & Content \\
\hline 1. Obtain sample models & 3D human body shape model data are used. \\
\hline 2. Classify sample models & Sample models are classified based on the range of the section by the representative grid. \\
\hline 3. Select template model & One template model is selected in the range of important variables \pm 10 mm for each representative grid. \\
\hline 4. Select sample model & Based on the similarity to the template model, five sample models are selected for each representative grid. \\
\hline 5. Body-section analysis & $\begin{array}{c}\text { Body sections, including the body cross-sections, longitudinal-sections, and side seams of the five sample } \\
\text { models, are extracted for each representative model. }\end{array}$ \\
\hline 6. Generate average wireframe & Average body sections are generated by averaging each extracted section. \\
\cline { 2 - 2 } 7. Body cross-section modeling & $\begin{array}{c}\text { An average wireframe is generated based on the average body sections. } \\
\text { modeling is performed based on the template model, and the cross-section models are merged into one. }\end{array}$ \\
\hline
\end{tabular}

\subsubsection{Segmenting the Size Section}

To obtain sample data, 2D human body measurement data of 199 Korean adult males provided by the human body measurement database of the sixth Size-Korea project (2010) were used.

To select the important variables of height, hip circumference, and lower-drop, the body-size variables defining the standard body shapes of adult males were selected. Height is an important variable associated with body size; hip circumference is an important variable associated with volume, and lower-drop (the difference between the hip circumstance and the waist circumstance (omphalion)) is an important variable associated with physical features.

To segment the important variables into sections, they were evenly divided into 10 section along a range of minimum-maximum values, 10 size sections were generated as shown in Table 4, and the normal distribution of 10 equally divided sections was confirmed through frequency analysis of the size sections for each important variable.

In the primary cross-tabulation analysis, the dimensions of the important height and hip circumference variable are coded on a nominal scale of 10 sections using the SPSS statistics analysis program, and then cross-tabulation analysis is performed to determine the distribution of the size section between the height and hip circumference important variables. The calculation results of primary cross-tabulation are shown in Table 5. The chi-square value was 71.465 and the $p$-value was 0.049 . Since $p<0.05$, it was confirmed that the difference between groups was statistically significant. As for height, section 6 showed the highest frequency with $23.6 \%$. As for hip circumference, section 5 showed the highest frequency with $23.6 \%$. 
Table 4. Division of important variable section.

\begin{tabular}{ccccccc}
\hline Section & $\begin{array}{c}\text { Height } \\
(\mathbf{m m})\end{array}$ & Freq. & $\begin{array}{c}\text { Hip Circumference } \\
(\mathbf{m m})\end{array}$ & Freq. & $\begin{array}{c}\text { Lower-Drop } \\
(\mathbf{m m})\end{array}$ & Freq. \\
\hline 1 & $1542-1573$ & 1 & $796-827$ & 1 & $0-20$ & 10 \\
\hline 2 & $1573-1604$ & 5 & $827-858$ & 3 & $20-40$ & 13 \\
\hline 3 & $1604-1635$ & 10 & $858-889$ & 17 & $40-60$ & 21 \\
\hline 4 & $1635-1666$ & 18 & $889-920$ & 38 & $60-80$ & 27 \\
\hline 5 & $1666-1697$ & 22 & $920-951$ & 47 & $80-100$ & 32 \\
\hline 6 & $1697-1728$ & 47 & $951-982$ & 42 & $100-120$ & 33 \\
\hline 7 & $1728-1759$ & 38 & $982-1013$ & 30 & $120-140$ & 26 \\
\hline 8 & $1759-1790$ & 32 & $1013-1044$ & 10 & $140-160$ & 19 \\
\hline 9 & $1790-1821$ & 13 & $1044-1075$ & 8 & $160-180$ & 14 \\
\hline 10 & $1821-1852$ & 13 & $1075-1106$ & 3 & $180-199$ & 4 \\
\hline
\end{tabular}

Table 5. Results of primary cross-tabulation calculation.

\begin{tabular}{|c|c|c|c|c|c|c|c|c|c|c|c|c|c|}
\hline & & \multicolumn{11}{|c|}{ Section of Hip Circumference } & \multirow[t]{2}{*}{ Total } \\
\hline & & & 1 & 2 & 3 & 4 & 5 & 6 & 7 & 8 & 9 & 10 & \\
\hline \multirow{20}{*}{$\begin{array}{l}\text { Section of } \\
\text { height }\end{array}$} & \multirow{2}{*}{1} & Freq. & 0 & 0 & 1 & 0 & 0 & 0 & 0 & 0 & 0 & 0 & 1 \\
\hline & & total $\%$ & $0.0 \%$ & $0.0 \%$ & $0.5 \%$ & $0.0 \%$ & $0.0 \%$ & $0.0 \%$ & $0.0 \%$ & $0.0 \%$ & $0.0 \%$ & $0.0 \%$ & $0.5 \%$ \\
\hline & \multirow{2}{*}{2} & Freq. & 0 & 0 & 1 & 2 & 0 & 2 & 0 & 0 & 0 & 0 & 5 \\
\hline & & total $\%$ & $0.0 \%$ & $0.0 \%$ & $0.5 \%$ & $1.0 \%$ & $0.0 \%$ & $1.0 \%$ & $0.0 \%$ & $0.0 \%$ & $0.0 \%$ & $0.0 \%$ & $2.5 \%$ \\
\hline & \multirow{2}{*}{3} & Freq. & 1 & 1 & 1 & 1 & 3 & 2 & 1 & 0 & 0 & 0 & 10 \\
\hline & & total \% & $0.5 \%$ & $0.5 \%$ & $0.5 \%$ & $0.5 \%$ & $1.5 \%$ & $1.0 \%$ & $0.5 \%$ & $0.0 \%$ & $0.0 \%$ & $0.0 \%$ & $5.0 \%$ \\
\hline & \multirow{2}{*}{4} & Freq. & 0 & 0 & 2 & 8 & 3 & 3 & 2 & 0 & 0 & 0 & 18 \\
\hline & & total $\%$ & $0.0 \%$ & $0.0 \%$ & $1.0 \%$ & $4.0 \%$ & $1.5 \%$ & $1.5 \%$ & $1.0 \%$ & $0.0 \%$ & $0.0 \%$ & $0.0 \%$ & $9.0 \%$ \\
\hline & \multirow{2}{*}{5} & Freq. & 0 & 1 & 2 & 5 & 5 & 6 & 2 & 0 & 1 & 0 & 22 \\
\hline & & total \% & $0.0 \%$ & $0.5 \%$ & $1.0 \%$ & $2.5 \%$ & $2.5 \%$ & $3.0 \%$ & $1.0 \%$ & $0.0 \%$ & $0.5 \%$ & $0.0 \%$ & $11.1 \%$ \\
\hline & \multirow{2}{*}{6} & Freq. & 0 & 1 & 5 & 12 & 13 & 8 & 6 & 1 & 1 & 0 & 47 \\
\hline & & total $\%$ & $0.0 \%$ & $0.5 \%$ & $2.5 \%$ & $6.0 \%$ & $6.5 \%$ & $4.0 \%$ & $3.0 \%$ & $0.5 \%$ & $0.5 \%$ & $0.0 \%$ & $23.6 \%$ \\
\hline & \multirow{2}{*}{7} & Freq. & 0 & 0 & 1 & 8 & 9 & 10 & 7 & 3 & 0 & 0 & 38 \\
\hline & & total \% & $0.0 \%$ & $0.0 \%$ & $0.5 \%$ & $4.0 \%$ & $4.5 \%$ & $5.0 \%$ & $3.5 \%$ & $1.5 \%$ & $0.0 \%$ & $0.0 \%$ & $19.1 \%$ \\
\hline & \multirow{2}{*}{8} & Freq. & 0 & 0 & 3 & 1 & 8 & 7 & 7 & 3 & 2 & 1 & 32 \\
\hline & & total \% & $0.0 \%$ & $0.0 \%$ & $1.5 \%$ & $0.5 \%$ & $4.0 \%$ & $3.5 \%$ & $3.5 \%$ & $1.5 \%$ & $1.0 \%$ & $0.5 \%$ & $16.1 \%$ \\
\hline & \multirow{2}{*}{9} & Freq. & 0 & 0 & 1 & 1 & 3 & 1 & 3 & 2 & 1 & 1 & 13 \\
\hline & & total \% & $0.0 \%$ & $0.0 \%$ & $0.5 \%$ & $0.5 \%$ & $1.5 \%$ & $0.5 \%$ & $1.5 \%$ & $1.0 \%$ & $0.5 \%$ & $0.5 \%$ & $6.5 \%$ \\
\hline & \multirow{2}{*}{10} & Freq. & 0 & 0 & 0 & 0 & 3 & 3 & 2 & 1 & 3 & 1 & 13 \\
\hline & & total $\%$ & $0.0 \%$ & $0.0 \%$ & $0.0 \%$ & $0.0 \%$ & $1.5 \%$ & $1.5 \%$ & $1.0 \%$ & $0.5 \%$ & $1.5 \%$ & $0.5 \%$ & $6.5 \%$ \\
\hline \multirow{2}{*}{\multicolumn{2}{|c|}{ total }} & Freq. & 1 & 3 & 17 & 38 & 47 & 42 & 30 & 10 & 8 & 3 & 199 \\
\hline & & total \% & $0.5 \%$ & $1.5 \%$ & $8.5 \%$ & $19.1 \%$ & $23.6 \%$ & $21.1 \%$ & $15.1 \%$ & $5.0 \%$ & $4.0 \%$ & $1.5 \%$ & $100.0 \%$ \\
\hline
\end{tabular}

The process of section removal and grouping in primary cross-tabulation analysis was as follows. In the cross-tabulation, the initial 100 sections were filtered down to 63 by removing hip-circumference sections 1, 2, and 10 and height section 1, which were the maximum-minimum extrema with a total appearance frequency of less than $2 \%$. Next, 12 sections with an appearance frequency of $0 \%$ were deleted to filter the 63 sections to 51 (Figure 2a). Then, the sections were grouped based on the coverage rate of 2 to $6.5 \%$ to filter the 51 sections to 25 (Figure $2 \mathrm{~b}$ ). In the primary cross-tabulation analysis, 25 primary 
size sections with a total coverage rate of $95.5 \%$ were generated based on height and hip circumference data through the interpretation of the cross-tabulation, as shown in Table 6.

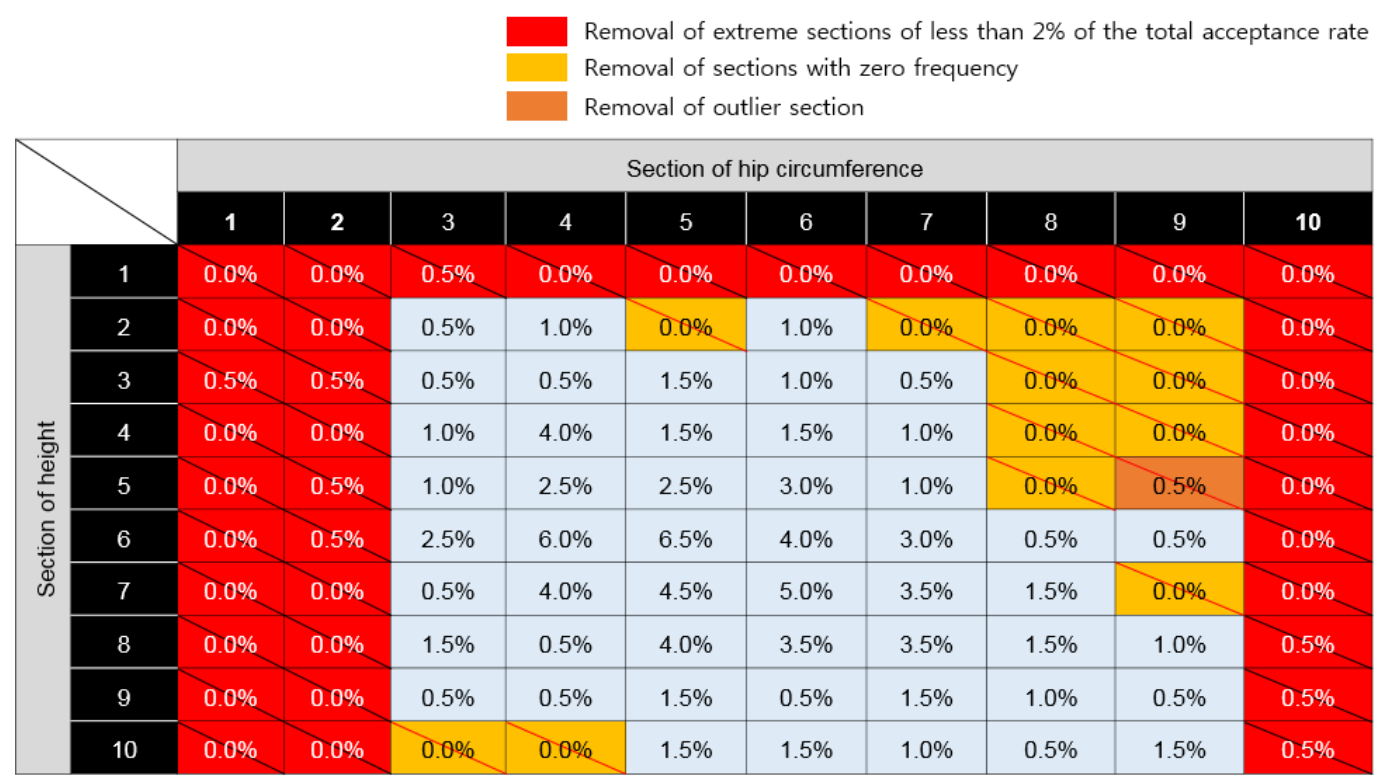

(a)

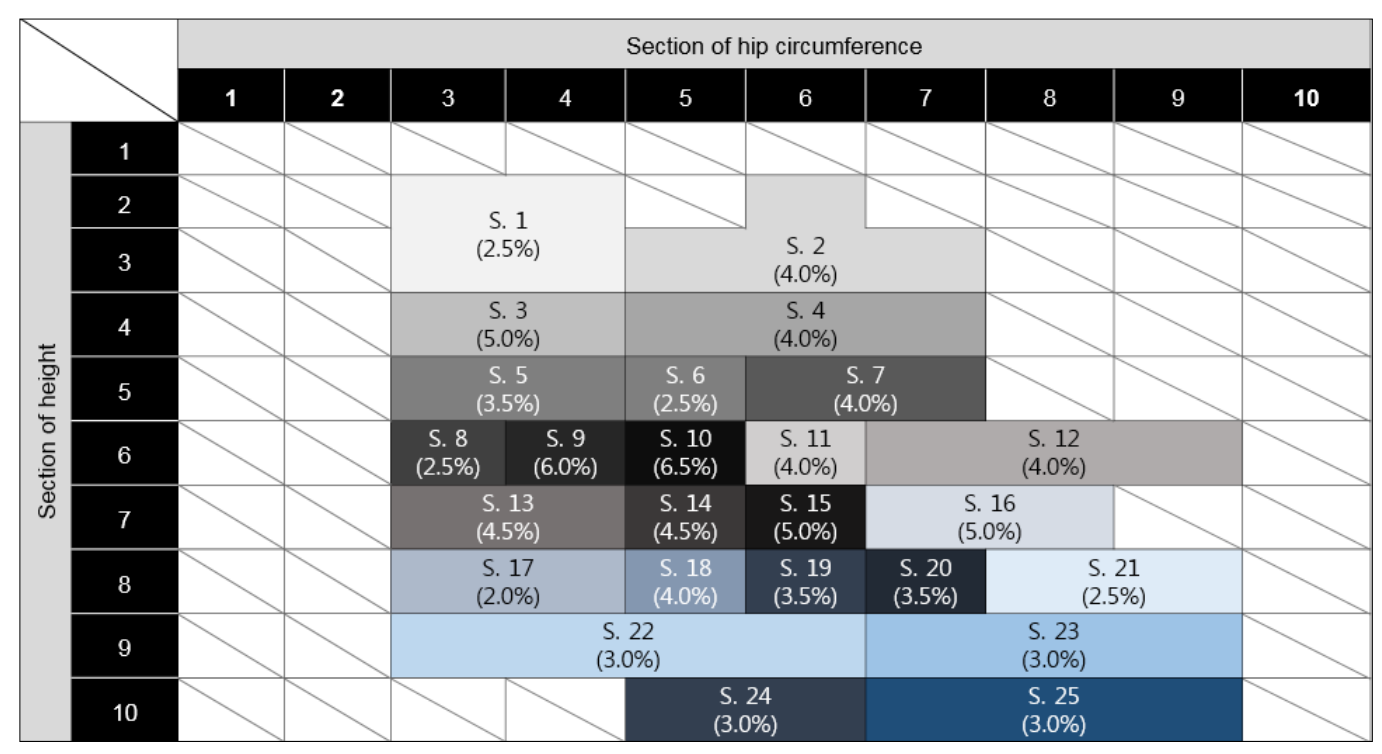

(b)

Figure 2. Section removal and grouping process of primary cross-tabulation: (a) section removal and (b) section grouping. 
Table 6. Results of primary cross-tabulation analysis.

\begin{tabular}{|c|c|c|c|c|}
\hline Section & $\begin{array}{l}\text { Height } \\
\text { (mm) }\end{array}$ & $\begin{array}{l}\text { Hip Circumference } \\
(\mathrm{mm})\end{array}$ & Freq. & $\begin{array}{c}\text { Coverage Rate } \\
(\%)\end{array}$ \\
\hline 1 & 1573-1635 & $858-920$ & 5 & 2.5 \\
\hline 2 & $1573-1635$ & 920-1013 & 8 & 4.0 \\
\hline 3 & 1635-1666 & 858-920 & 10 & 5.0 \\
\hline 4 & 1635-1666 & 920-1013 & 8 & 4.0 \\
\hline 5 & 1666-1697 & $858-920$ & 7 & 3.5 \\
\hline 6 & 1666-1697 & 920-951 & 5 & 2.5 \\
\hline 7 & 1666-1697 & 951-1013 & 8 & 4.0 \\
\hline 8 & $1697-1728$ & $858-889$ & 5 & 2.5 \\
\hline 9 & $1697-1728$ & 889-920 & 12 & 6.0 \\
\hline 10 & $1697-1728$ & 920-951 & 13 & 6.5 \\
\hline 11 & $1697-1728$ & $951-982$ & 8 & 4.0 \\
\hline 12 & $1697-1728$ & 982-1075 & 8 & 4.0 \\
\hline 13 & 1728-1759 & 858-920 & 9 & 4.5 \\
\hline 14 & 1728-1759 & 920-951 & 9 & 4.5 \\
\hline 15 & 1728-1759 & $951-982$ & 10 & 5.0 \\
\hline 16 & 1728-1759 & 982-1044 & 10 & 5.0 \\
\hline 17 & $1759-1790$ & 858-920 & 4 & 2.0 \\
\hline 18 & 1759-1790 & 920-951 & 8 & 4.0 \\
\hline 19 & 1759-1790 & 951-982 & 7 & 3.5 \\
\hline 20 & 1759-1790 & 982-1013 & 7 & 3.5 \\
\hline 21 & 1759-1790 & 1013-1075 & 5 & 2.5 \\
\hline 22 & 1790-1821 & 858-982 & 6 & 3.0 \\
\hline 23 & 1790-1821 & 982-1075 & 6 & 3.0 \\
\hline 24 & $1821-1852$ & 920-982 & 6 & 3.0 \\
\hline \multirow[t]{2}{*}{25} & 1821-1852 & 982-1075 & 6 & 3.0 \\
\hline & Total & & 190 & 95.5 \\
\hline
\end{tabular}

In the secondary cross-tabulation analysis, after data coding of the height and hip circumference important variable dimension into 25 sections and the lower-drop important variable dimension into 10 sections, cross-tabulation analysis was performed to determine the distribution of the size section between the height and hip circumference and the lower-drop variable. The calculation results of secondary cross-tabulation are shown in Table 7. The chi-square value was 269.041, and the $p$-value was 0.008 . Since $p<0.05$, it was confirmed that the difference between groups was statistically significant. In the height and hip circumference, section 10 showed the highest frequency with $6.8 \%$. In the lower-drop, sections 5 and 6 showed the highest frequency with $16.8 \%$. 
Table 7. Results of secondary cross-tabulation calculation.

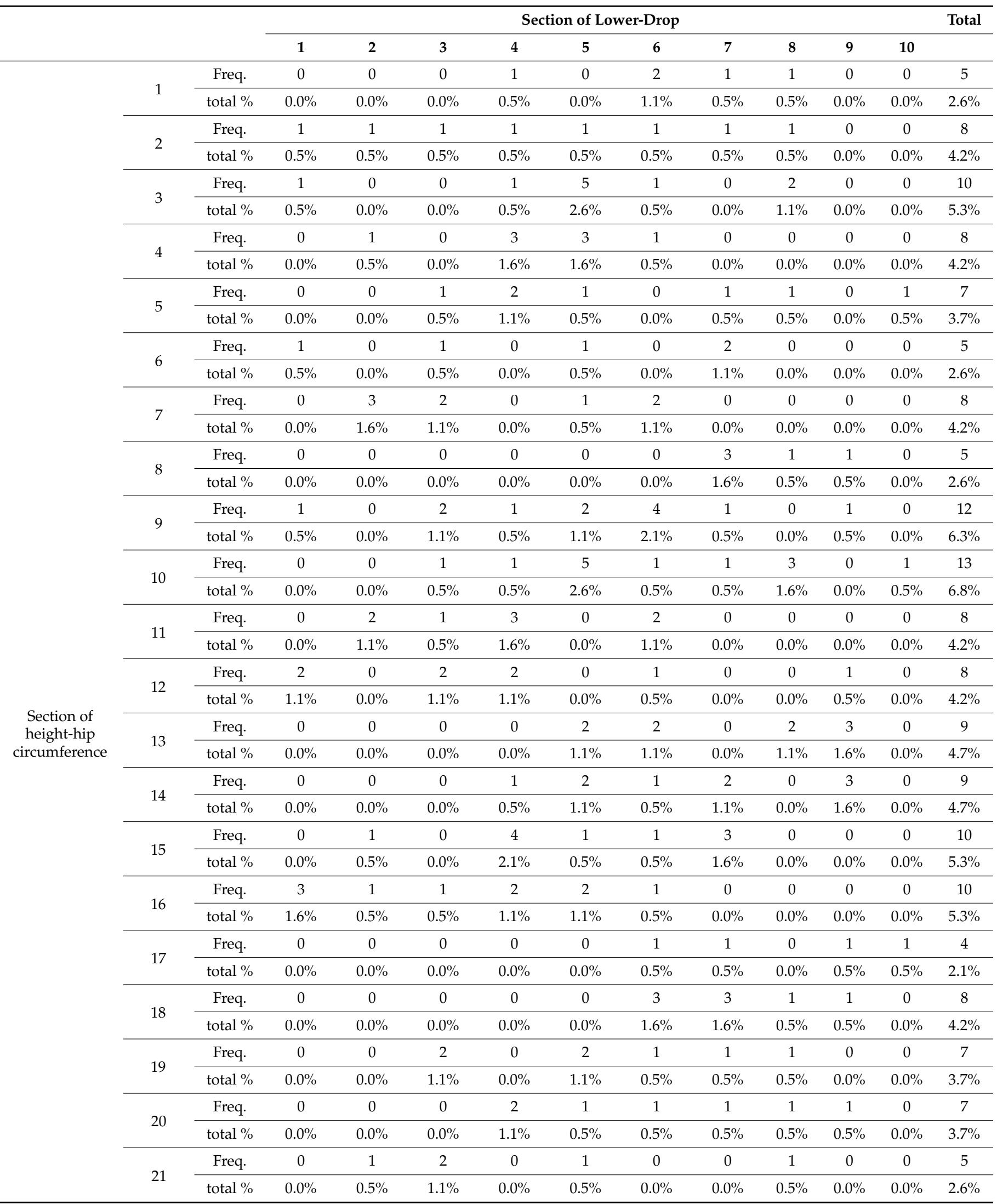


Table 7. Cont.

\begin{tabular}{|c|c|c|c|c|c|c|c|c|c|c|c|c|c|}
\hline & & & \multicolumn{10}{|c|}{ Section of Lower-Drop } & \multirow[t]{2}{*}{ Total } \\
\hline & & & 1 & 2 & 3 & 4 & 5 & 6 & 7 & 8 & 9 & 10 & \\
\hline & \multirow{2}{*}{22} & Freq. & 0 & 0 & 0 & 0 & 1 & 2 & 2 & 0 & 1 & 0 & 6 \\
\hline & & total $\%$ & $0.0 \%$ & $0.0 \%$ & $0.0 \%$ & $0.0 \%$ & $0.5 \%$ & $1.1 \%$ & $1.1 \%$ & $0.0 \%$ & $0.5 \%$ & $0.0 \%$ & $3.2 \%$ \\
\hline & \multirow{2}{*}{23} & Freq. & 0 & 0 & 3 & 1 & 0 & 0 & 1 & 1 & 0 & 0 & 6 \\
\hline & & total $\%$ & $0.0 \%$ & $0.0 \%$ & $1.6 \%$ & $0.5 \%$ & $0.0 \%$ & $0.0 \%$ & $0.5 \%$ & $0.5 \%$ & $0.0 \%$ & $0.0 \%$ & $3.2 \%$ \\
\hline & \multirow{2}{*}{24} & Freq. & 0 & 0 & 0 & 1 & 0 & 2 & 0 & 3 & 0 & 0 & 6 \\
\hline & & total $\%$ & $0.0 \%$ & $0.0 \%$ & $0.0 \%$ & $0.5 \%$ & $0.0 \%$ & $1.1 \%$ & $0.0 \%$ & $1.6 \%$ & $0.0 \%$ & $0.0 \%$ & $3.2 \%$ \\
\hline & \multirow{2}{*}{25} & Freq. & 0 & 1 & 0 & 1 & 1 & 2 & 1 & 0 & 0 & 0 & 6 \\
\hline & & total $\%$ & $0.0 \%$ & $0.5 \%$ & $0.0 \%$ & $0.5 \%$ & $0.5 \%$ & $1.1 \%$ & $0.5 \%$ & $0.0 \%$ & $0.0 \%$ & $0.0 \%$ & $3.2 \%$ \\
\hline \multirow{2}{*}{ total } & & Freq. & 9 & 11 & 19 & 27 & 32 & 32 & 25 & 19 & 13 & 3 & 190 \\
\hline & & total $\%$ & $4.7 \%$ & $5.8 \%$ & $10.0 \%$ & $14.2 \%$ & $16.8 \%$ & $16.8 \%$ & $13.2 \%$ & $10.0 \%$ & $6.8 \%$ & $1.6 \%$ & $100.0 \%$ \\
\hline
\end{tabular}

The process of section removal and grouping in secondary cross-tabulation analysis is as follows. In the cross-tabulation, the initial 250 were filtered down to 225 by removing the lower-drop section 10, which was the maximum-minimum extreme section with a total appearance frequency of less than $2 \%$. Next, 108 sections with an appearance frequency of $0 \%$ were deleted to filter the 225 sections down to 117 , and seven sections showing the lowest appearance frequency in the maximum-minimum extreme section of height and hip circumference were removed to provide 110 sections (Figure 3a). Then, those sections were grouped based on the coverage rate of 2 to $4.3 \%$ to filter the 110 sections into 34 (Figure 3(b1,2)). These were grouped again based on the coverage rate of 4.2 to $7.3 \%$ to filter the 34 sections into the final 18 (Figure 3c). In the secondary cross-tabulation analysis, 18 final sections with a total coverage rate of $90.5 \%$ were generated based on height, hip circumference, and lower-drop data from the interpretation of the cross-tabulation, as shown in Table 8.

The number of general size sections applied to clothes, shoes, gloves, hats, etc., ranges from 5 to 10 . Considering that these products are products with relatively high design tolerances compared to the products under study, it was considered appropriate to determine the number of size sections of body shape fit between 15 and 20. In addition, assuming that the number of size sections is, at most, 20, the coverage rate of each size section is selected based on an approximate value of $5 \%$. Based on the criteria for excluding extreme sections of less than the 5 th $\%$ and more than the 95 th $\%$ in product size design reflecting human dimensions, the total coverage rate was set as a target of $90 \%$. The proposed size system-based 3DP-pHRI is a method that selects the 3DP-pHRI size system that is closest to the human body shape of the wearer from the previously developed (libraryized) pHRI and produces it using 3D printing. In this respect, the number of size sections is not subject to a large limitation; however, setting a size section that is too compact can complicate the process of selecting a size system suitable for the wearer. Accordingly, 18 size sections were finally selected in consideration of the human fitness (total coverage rate: $90.5 \%$ ), as shown in Table 8 .

The characteristics of each section of the selected size section are as follows. Based on the height and hip circumference important variable, sections 1 to 3 correspond to the lower $14.5 \%$ range, sections 16 to 18 correspond to the upper $16.5 \%$ range, and sections 4 to 15 correspond to the median $59.5 \%$ range. Based on the important lower-drop variable, the lower sections 1-3 and the upper sections 16-18 have a single category, and the 12 size sections of the median sections 4-15 are size sections with three different body shape ratios (thin, normal, and fat). According to the characteristics of this size section, it can be seen that the generated size section has a size division that appropriately reflects the shape of the human body. 


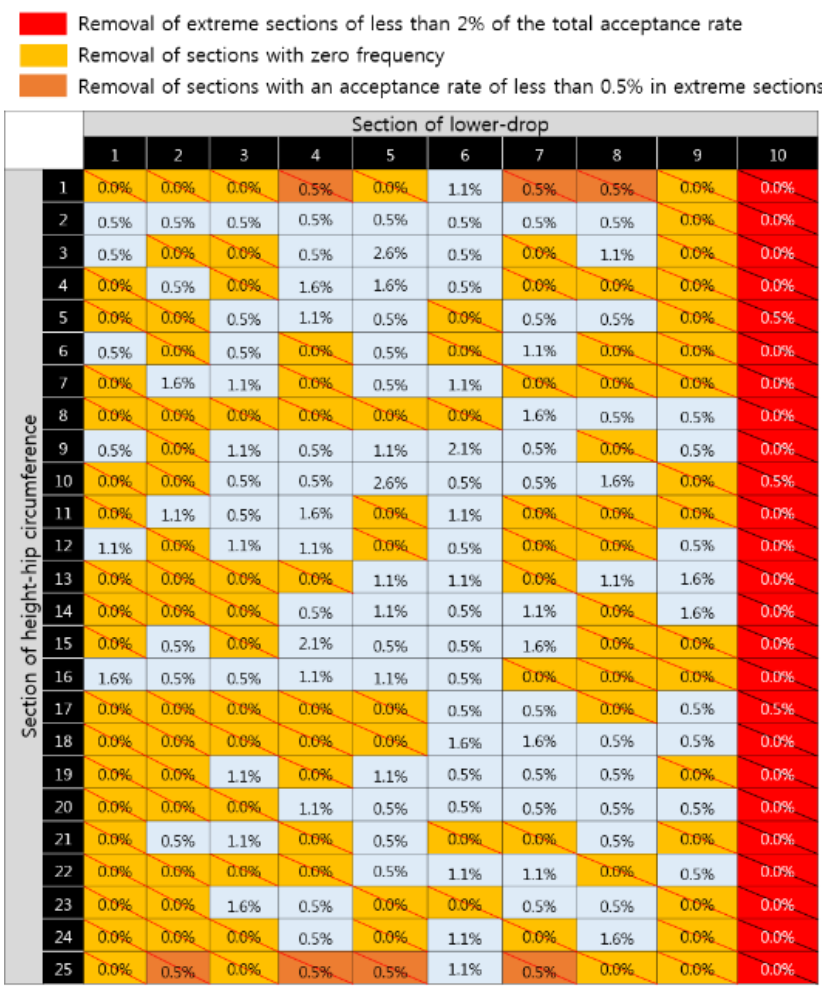

(a)

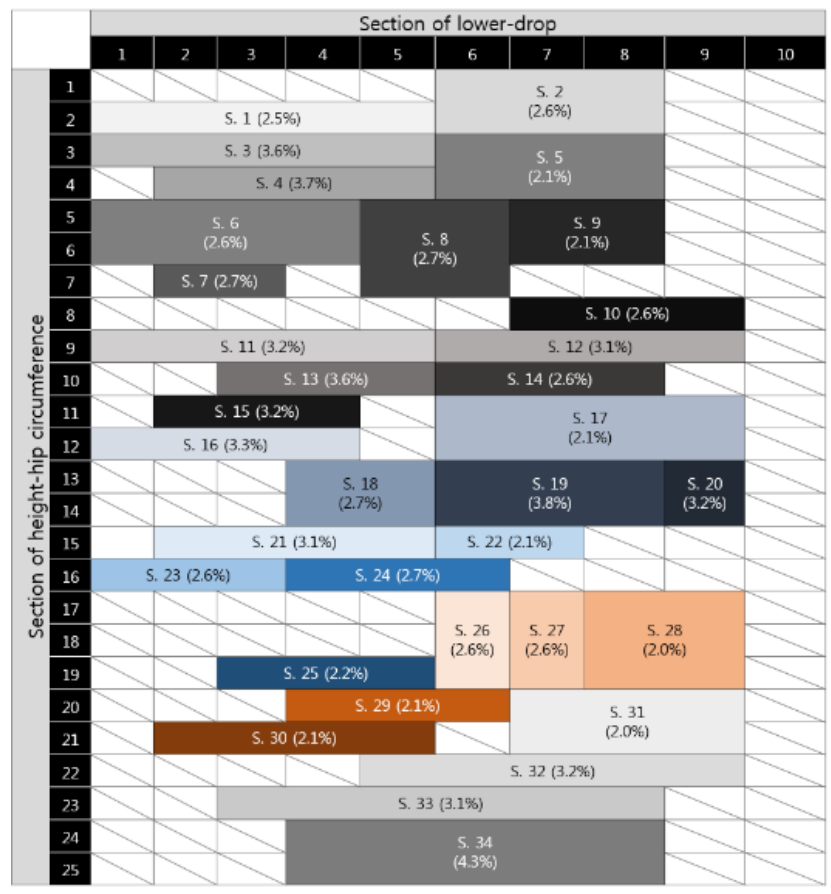

(b2)

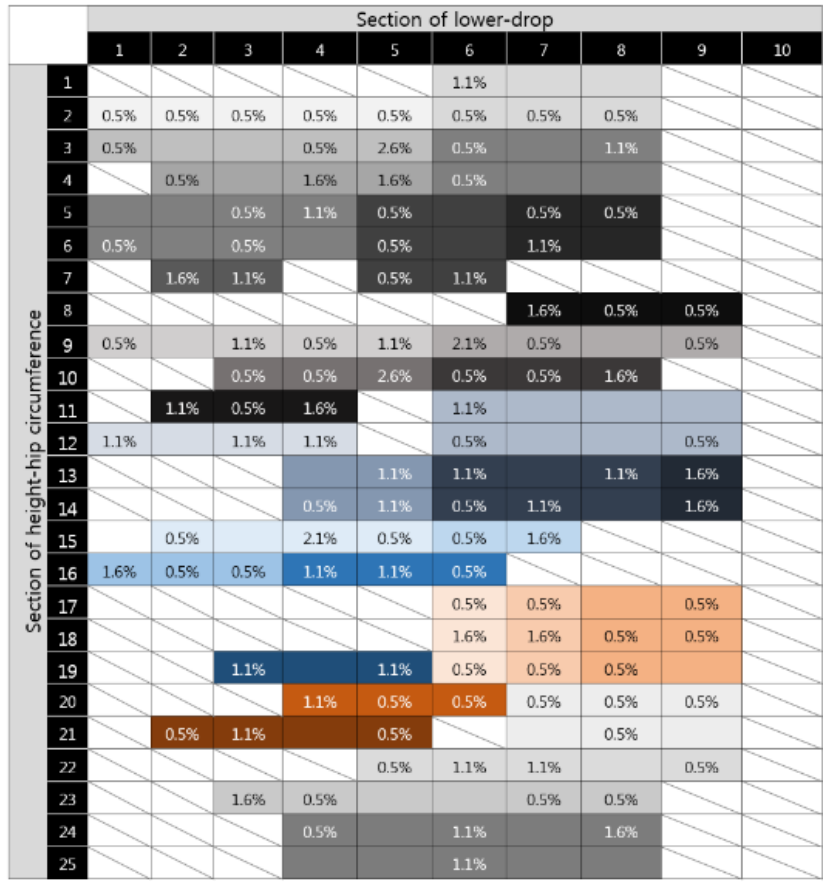

(b1)

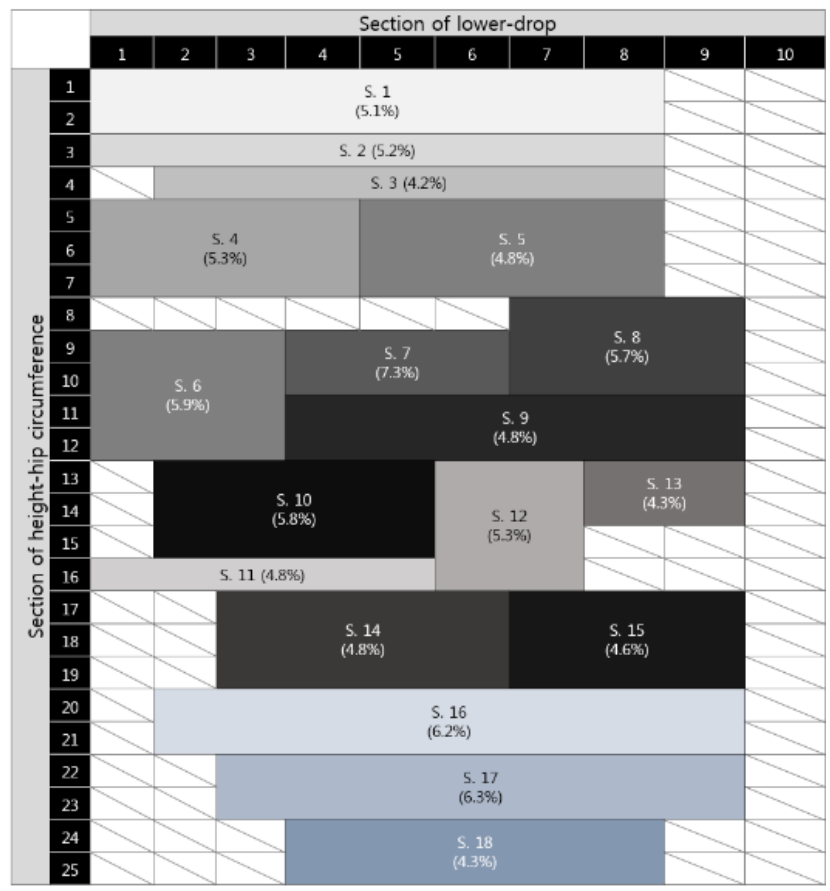

(c)

Figure 3. Section removal and grouping process of secondary cross-tabulation: (a) section removal; (b1) 1st section grouping-coverage rate-based classification; (b2) 1st section grouping-summation of coverage rates and section numbering; (c) 2nd section grouping. 
Table 8. Results of secondary cross-tabulation analysis.

\begin{tabular}{cccccc}
\hline Section & $\begin{array}{c}\text { Height } \\
\mathbf{( M m})\end{array}$ & $\begin{array}{c}\text { Hip Circumference } \\
\mathbf{( M m})\end{array}$ & $\begin{array}{c}\text { Lower-Drop } \\
\mathbf{( M m})\end{array}$ & Freq. & $\begin{array}{c}\text { Coverage Rate } \\
\mathbf{( \% )}\end{array}$ \\
\hline 1 & $1573-1635$ & $858-1013$ & $0-180$ & 10 & 5.0 \\
\hline 2 & $1635-1666$ & $858-920$ & $0-180$ & 10 & 5.0 \\
\hline 3 & $1635-1666$ & $920-1013$ & $0-180$ & 8 & 4.0 \\
\hline 4 & $1666-1697$ & $858-1013$ & $0-80$ & 10 & 5.0 \\
\hline 5 & $1666-1697$ & $858-1013$ & $80-180$ & 9 & 4.5 \\
\hline 6 & $1697-1728$ & $858-1075$ & $0-60$ & 11 & 5.5 \\
\hline 7 & $1697-1728$ & $858-951$ & $60-120$ & 14 & 7.0 \\
\hline 8 & $1697-1728$ & $858-951$ & $120-180$ & 11 & 5.5 \\
\hline 9 & $1697-1728$ & $951-1075$ & $60-180$ & 9 & 4.5 \\
\hline 10 & $1728-1759$ & $858-982$ & $0-100$ & 11 & 5.5 \\
\hline 11 & $1728-1759$ & $982-1044$ & $0-100$ & 9 & 4.5 \\
\hline 12 & $1728-1759$ & $858-1044$ & $100-140$ & 10 & 5.0 \\
\hline 13 & $1728-1759$ & $858-1044$ & $140-180$ & 8 & 4.0 \\
\hline 14 & $1759-1790$ & $858-982$ & $0-120$ & 9 & 4.5 \\
\hline 15 & $1759-1790$ & $858-982$ & $120-180$ & 9 & 4.5 \\
\hline 16 & $1759-1790$ & $982-1075$ & $0-180$ & 12 & 6.0 \\
\hline 17 & $1790-1821$ & $858-1075$ & $0-180$ & 12 & 6.0 \\
\hline 18 & $1821-1852$ & $920-1075$ & $0-180$ & 8 & 4.0 \\
\hline & & Total & & 180 & \\
\hline & & & & & 9.5 \\
\hline
\end{tabular}

When forming the representative grid, the 180 sample data points included in the size section were plotted on a 3D scatterplot based on three important variables: height, hip circumference, and lower-drop (Figure 4a). A representative grid for each of the 18 size sections generated by cross-analysis were then formed (Figure $4 \mathrm{~b}$ ). Each generated size section was used as a reference size section to classify the sample models during average human body model generation.

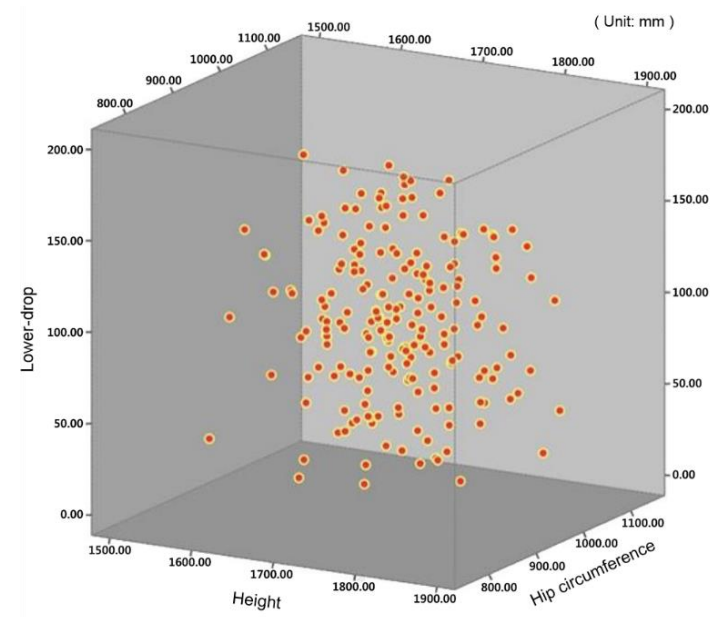

(a)

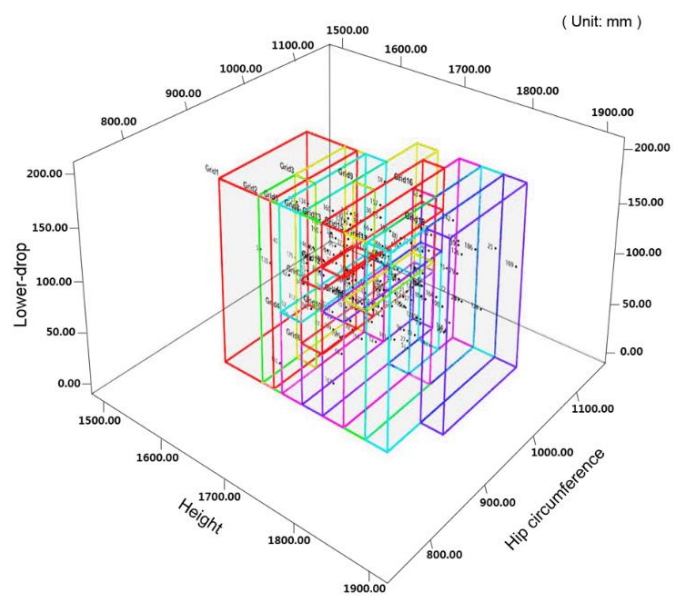

(b)

Figure 4. Results of representative grid method: (a) results of 3D scatter plot generation and (b) result of formation of representative grid by size section. 
When generating the sizes of important variables for each representative grid, the mean height, hip circumference, and lower-drop values of the sample data included in each representative grid were calculated to generate the size of important variables for each representative grid, as shown in Table 9, and the generated size of important variables was used as the reference size for selecting the template model in the process of average human body model generation.

Table 9. Dimensions of important variables by representative grid.

\begin{tabular}{|c|c|c|c|}
\hline Section & Height (Mm) & Hip Circumference (Mm) & Lower-Drop (Mm) \\
\hline 1 & 1618 & 945 & 87 \\
\hline 2 & 1651 & 902 & 95 \\
\hline 3 & 1652 & 959 & 76 \\
\hline 4 & 1679 & 942 & 46 \\
\hline 5 & 1681 & 930 & 115 \\
\hline 6 & 1714 & 964 & 35 \\
\hline 7 & 1712 & 925 & 94 \\
\hline 8 & 1712 & 903 & 145 \\
\hline 9 & 1712 & 983 & 93 \\
\hline 10 & 1741 & 950 & 75 \\
\hline 11 & 1739 & 1009 & 48 \\
\hline 12 & 1738 & 941 & 118 \\
\hline 13 & 1739 & 915 & 165 \\
\hline 14 & 1768 & 945 & 90 \\
\hline 15 & 1772 & 927 & 142 \\
\hline 16 & 1772 & 1013 & 99 \\
\hline 17 & 1803 & 971 & 104 \\
\hline 18 & 1836 & 980 & 120 \\
\hline
\end{tabular}

\subsubsection{Generation of Average Human Body Model by Section}

To obtain the sample models, the 3D human body shape model data of 195 Korean adult males provided by the human body measurement database of the sixth Size-Korea project (2010) were used.

To classify the 195 models obtained, 180 models in the range of the 18 size sections were used as samples, and they were classified according to the 18 size sections so that each section included about 10 sample models.

To select the template model, one model was selected in the $\pm 10 \mathrm{~mm}$ range of important variables dimensions for each representative grid. For sections 17 and 18, where no template model was detected, selection of a deviation range of $\pm 20 \mathrm{~mm}$ was made. For sections 4 and 9, where no template model was detected even within the deviation range of $\pm 20 \mathrm{~mm}$, selection was based on the data from the human body measurement database of the fifth Size-Korea project (2003 to 2004).

When selecting the sample models, five sample models were chosen based on the similarity to the selected template model for each representative grid after removing outliers based on ratio, posture, symmetry, and tendency from the classified sample models.

For body-section analysis, the five sample models selected for each section were preprocessed. The area excluding the upper part of the $20-\mathrm{cm}$ level above the waist (omphalion) and the lower part of the lateral malleolus was selected as the range of body-section analysis. Based on the 28 body sections consisting of 24 cross-sections, two longitudinal-sections, and two side seams, the body sections of each sample model were extracted (Figure 5). 

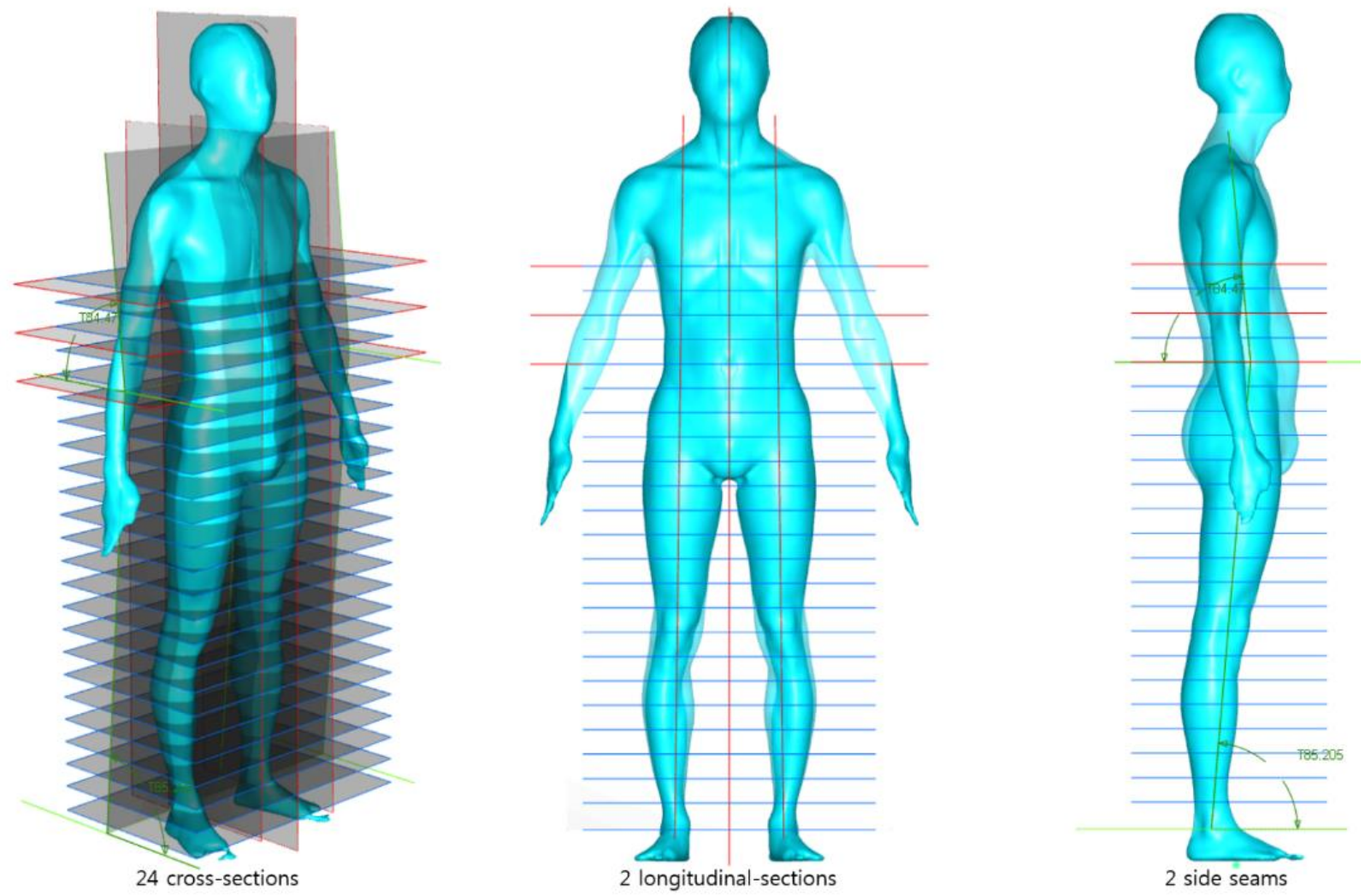

Figure 5. Reference plane for section analysis.

When generating an average wireframe, the average cross-sections, longitudinal sections, and side seams were generated by averaging each set extracted, and the average longitudinal sections and side seams were combined first, followed by the incorporation of the cross-sections (Figure 6). The same fixed values were used for the cross-section height, the longitudinal section width, and the side seam length, and the same reference plane was used for extracting the body sections.

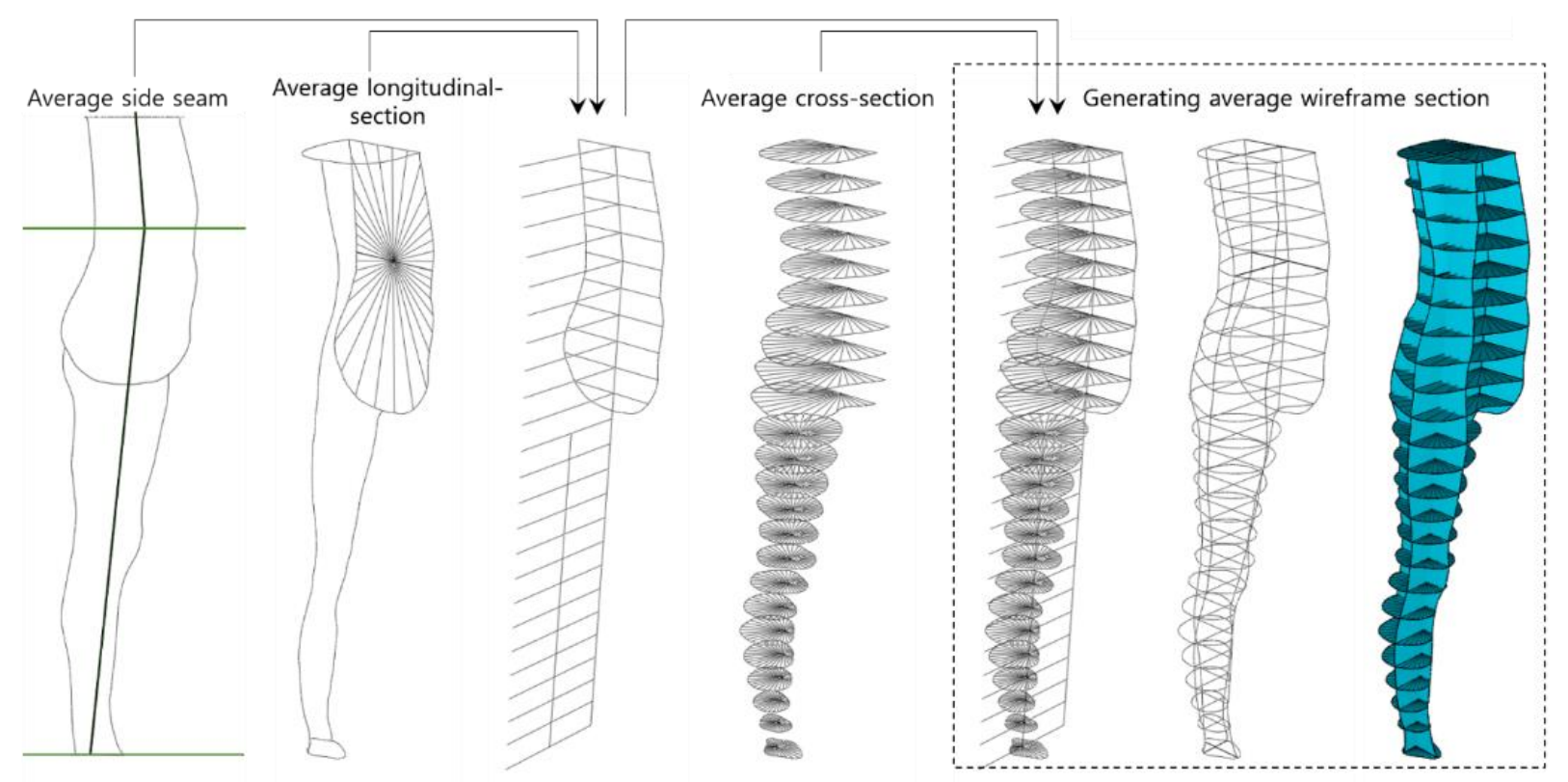

Figure 6. Process of average wireframe generation. 
To supplement the shape information between the cross-sections of the wireframe, body cross-section modeling was performed based on the template model, and the crosssection models were merged into one. The average human body model for each of the 18 size sections was created via body cross-section modeling, as shown in Figure 7. The data of the average human body model generated for each section were used as the reference surface shape data for the development of the 3DP-pHRI based on the size system.

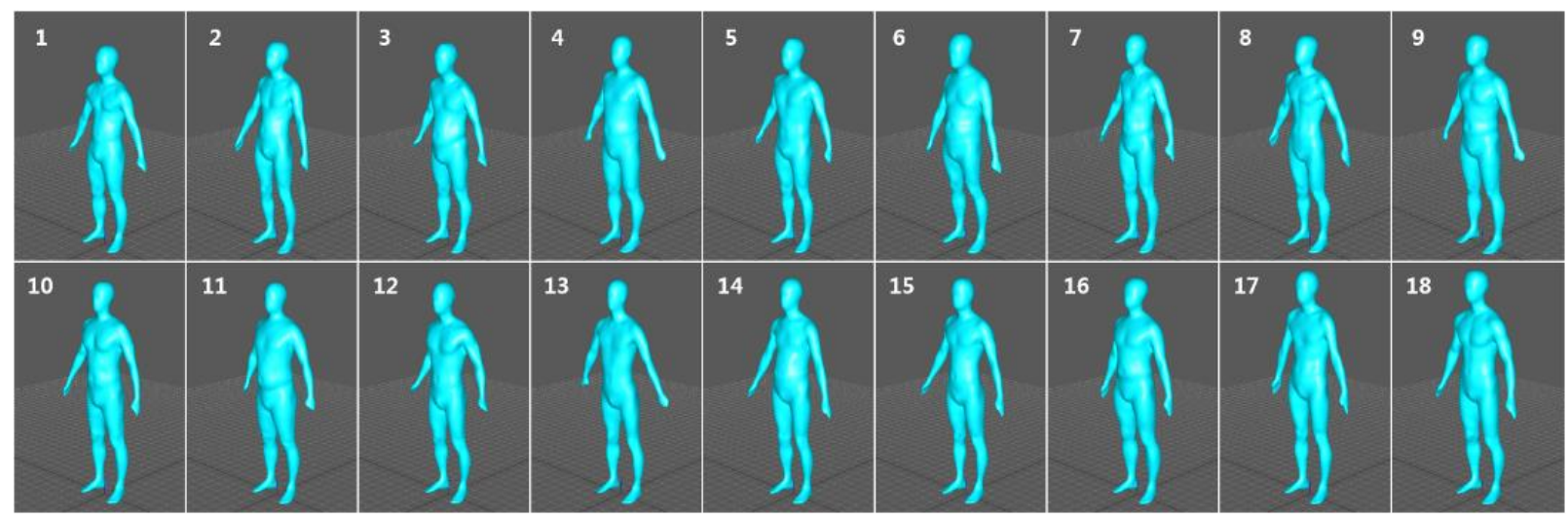

Figure 7. Results of average human body model generation by section.

\subsubsection{Development of 3DP-pHRI Based on Size System}

To develop the 3DP-pHRI based on the sizing system, the coordinate positions of the wearable robot model were adjusted in consideration of the connectivity between the average human body model for each section and the wearable robot. Based on the adjusted wearable robot model, postures (e.g., upper-lower body axis angle and leg spacing of each average human body model) were adjusted. Next, the basic shape models of the trunk and shank were developed in the order of section extraction, surface creation, front section removal and extension, shape boundary line trim, and thickness application by referring to the surface shape of each average human body model. Figure 8 shows an example for the process of developing the 3DP-pHRI based on the sizing system, and Figure 9 shows the results of developing the 3DP-pHRI in 18 size sections.

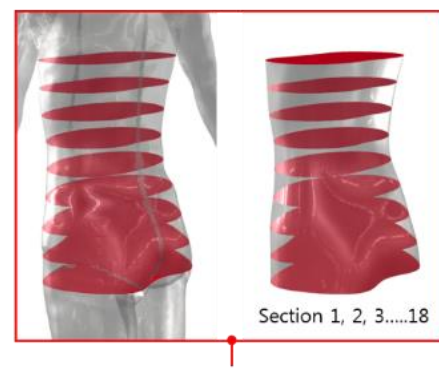

Section extraction and surface creation 1

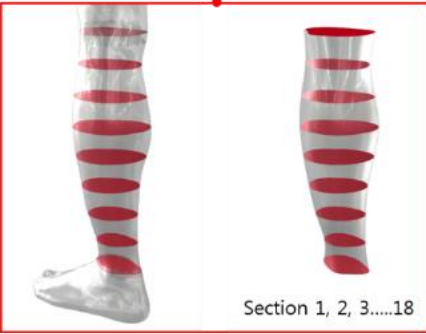

Procedure of development of trunk 3DP-pHRI

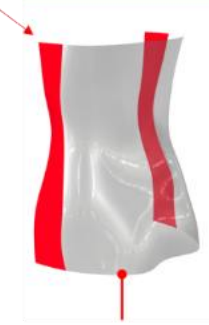

Front section removal and extension

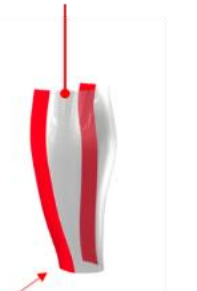

Procedure of development of shank 3DP-pHRI

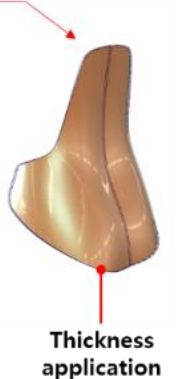

line trim

application

Figure 8. Procedure of development of 3DP-pHRI based on size system. 


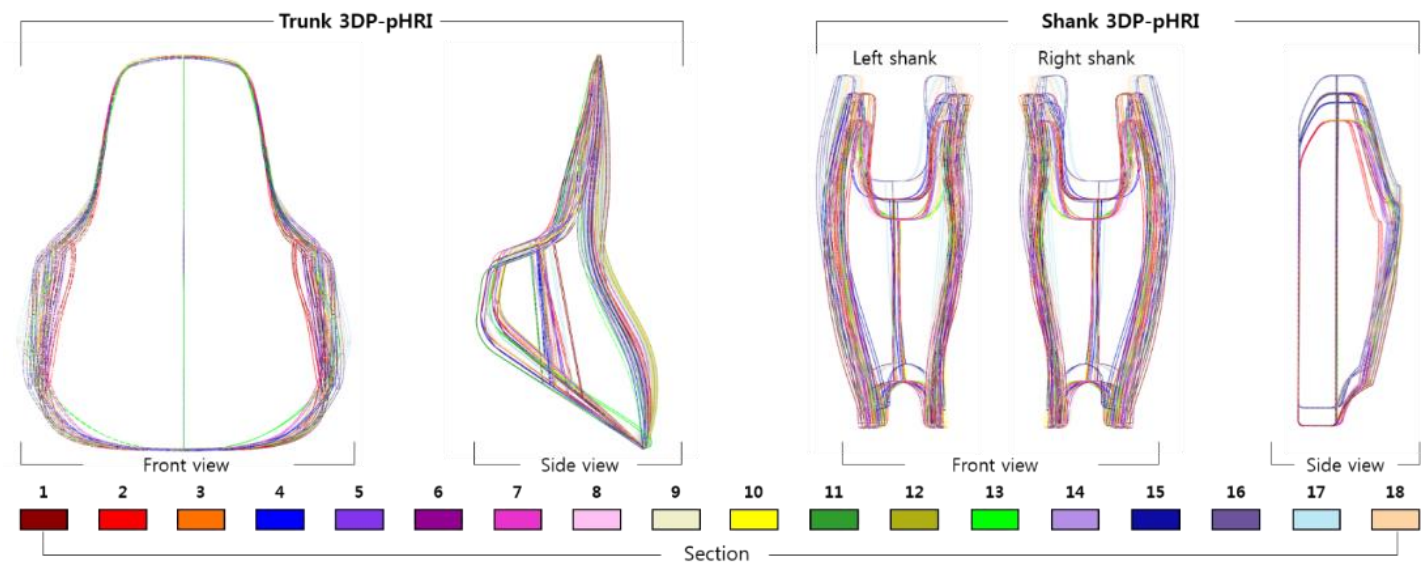

Figure 9. Result of development of 3DP-pHRI based on size system.

\section{Results and Discussion}

\subsection{Prototyping of 3DP-pHRI Based on the Sizing System}

In this study, a size system-based 3DP-pHRI is proposed as a new alternative that can implement the body shape-fit without need for 3D scanning of the body and the remodeling of the pHRI digital template model in the body shape-fit of a wearable robot using 3D printing. To this end, we propose an approach to library 3DP-pHRI into various sizes and shapes using the human body shape database. In Section 2.3, a total of 18 size sections were derived, and the size system of trunk and shank 3DP-pHRI was developed by referring to the surface shape of the average human model of each size section. To evaluate the conformity of the developed 3DP-pHRI's size system in shape and dimensions, prototyping was performed by 3D printing. In prototyping, FDM-type 3D printing equipment (NIPPO nanodaX, NANODAX CO., Ltd., Tokyo, Japan) with a nozzle diameter of $1 \mathrm{~mm}$ and a laminated layer thickness of $0.5 \mathrm{~mm}$, which can print large-sized digital models at a high speed, was used. A 3DP-pHRI based on the size system was fabricated using a PP material filament.

For the trunk, 18 sections were used. After excluding nine sections based on shape deviation analysis, nine sections were manufactured for the shank (Figure 10).
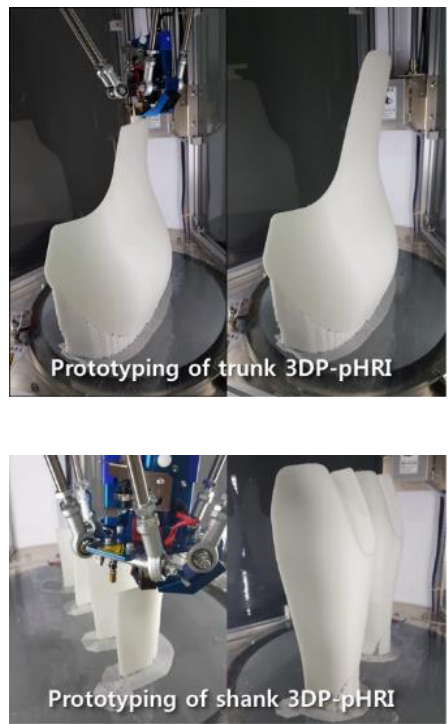

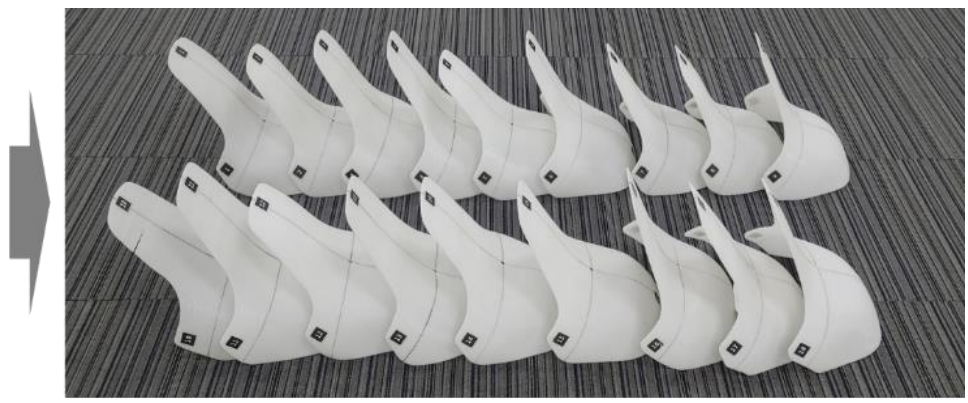

(a)

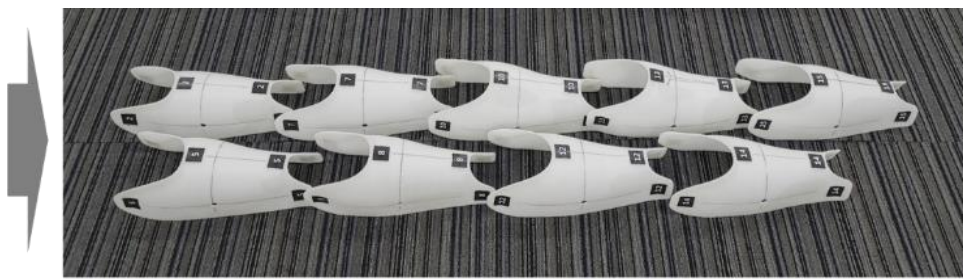

(b)

Figure 10. Results of 3DP-pHRI 3D printing: (a) 18 trunk 3DP-pHRI 3D printing and (b) nine shank 3DP-pHRI 3D printing results. 


\subsection{Evaluation of Conformity of Shape and Dimensions}

Regarding the conformity of shape and dimensions, the effectiveness of the 3DP-pHRI customization based on the sizing system was evaluated by visual observation and shape deviation analysis. Ten persons with paraplegia were selected as subjects for evaluation, and their physical information is shown in Table 10. In the visual observation, the 3DPpHRI prototyped using 3D printing was directly matched to the human body shape of the subject to be evaluated, and the trend of shape and dimensional suitability was confirmed. From the shape deviation analysis, the deviations between the human body shape data of 10 persons with paraplegia and the 3D model data of the trunk and shank 3DP-pHRIs selected for visual observation were examined to numerically analyze the conformity of shape and dimensions.

Table 10. Ten subjects' physical information.

\begin{tabular}{cccccccc}
\hline Gender & $\begin{array}{c}\text { Age } \\
\text { (Year) }\end{array}$ & $\begin{array}{c}\text { Height } \\
(\mathbf{c m})\end{array}$ & $\begin{array}{c}\text { Weight } \\
(\mathbf{k g})\end{array}$ & $\begin{array}{c}\text { Injury } \\
\text { Level }\end{array}$ & $\begin{array}{c}\text { ASIA } \\
\text { Scale }\end{array}$ & $\begin{array}{c}\text { Onset } \\
\text { (Year) }\end{array}$ \\
\hline Sub1 & male & 65 & 163 & 53 & T10 & A & 2006 \\
\hline Sub2 & male & 48 & 163 & 66 & L1 & C & 2004 \\
\hline Sub3 & male & 54 & 165 & 74 & T10 & A & 2005 \\
\hline Sub4 & male & 47 & 170 & 80 & L1 & A & 2015 \\
\hline Sub5 & male & 64 & 168 & 70 & C7 & C & 2011 \\
\hline Sub6 & male & 60 & 168 & 86 & T8 & A & 2006 \\
\hline Sub7 & male & 58 & 176 & 72 & T10 & A & 2007 \\
\hline Sub8 & male & 52 & 171 & 64 & T12 & A & 2001 \\
\hline Sub9 & male & 52 & 175 & 66.2 & T11 & A & 2013 \\
\hline Sub10 & male & 53 & 180 & 78 & T11 & A & 1992 \\
\hline
\end{tabular}

ASIA: American spinal cord injury association impairment scale.

\subsubsection{Evaluation by Visual Observation}

For reliable visual observations, each subject wore tights, and a standing traction device was used to induce a standing posture identical to the state of static balance while wearing a wearable robot. After completing the preparation process, the 3DP-pHRI, which was produced by estimating the location where the trunk and shank are equipped on the wearable robot, was directly matched to the human body shape of the subject, and the conformity of the shape and dimension was evaluated by visual observation (Figure 11).
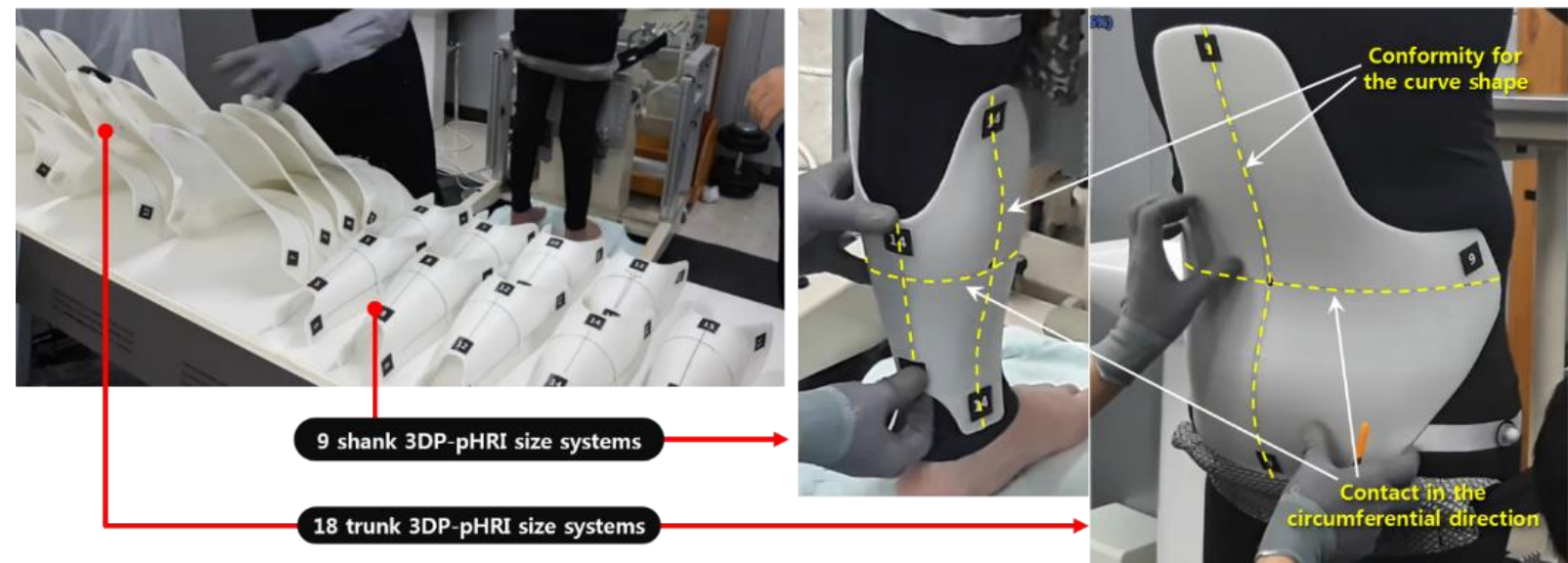

Figure 11. Scenes and criteria for evaluation by visual observation. 
In the visual observation of the trunk 3DP-pHRI, the trunk 3DP-pHRI, which showed the highest conformity in shape and dimensions, was selected as the sizing system based on the degree of conformity for the curve shape of the rear vertical section and the degree of contact in the circumferential direction. In the visual observation of the shank 3DP-pHRI, the shank 3DP-pHRI, which showed the highest conformity in shape and dimensions, was selected as the sizing system based on the degree of conformity for the curve shape of the side vertical section and the degree of contact in the circumferential direction (Figure 11).

Table 11 shows the results of selecting 18 trunk 3DP-pHRI size systems and nine shank 3DP-pHRI size systems according to the visual observation criteria for 10 persons with paraplegia. Trunk sections 4,5,9, and 16 were selected twice, and sections 6 and 10 were selected once. Shank sections 5, 10, and 14 were selected once, section 2 was twice, and section 7 was selected five times. The trunk and shank sizing systems selected showed conformity in shape and dimensions at an appropriate level for each subject. However, the shank system showed a biased tendency in the frequency of selection. Additionally, as with the selection results of trunk10-shank5 of Sub1, the trunk and shank sizing systems for each subject tended to be selected in different sections. This seems to have been caused by the body-shape specificity of people with paraplegia, who experience a decrease in the lower limb muscles because of disuse, which suggests that the shank 3DP-pHRI size system requires adjustments.

Table 11. Results of selecting 3DP-pHRI size systems.

\begin{tabular}{ccccccccccc}
\hline & Sub1 & Sub2 & Sub3 & Sub4 & Sub5 & Sub6 & Sub7 & Sub8 & Sub9 & Sub10 \\
\hline Trunk section & 10 & 5 & 6 & 9 & 4 & 16 & 16 & 5 & 4 & 9 \\
\hline Shank section & 5 & 14 & 7 & 10 & 7 & 7 & 7 & 2 & 7 & 2 \\
\hline
\end{tabular}

\subsubsection{Evaluation by Shape Deviation Analysis}

A handheld Artec Eva 3D scanner by Artec was used to extract the human body shape data of 10 persons with paraplegia. To obtain a surface shape close to the actual human body shape of the subject, 3D scanning was performed, while the subject wore tights in a standing posture using a traction device (Figure 12a). Figure 12b shows the human body shape data of 10 persons with paraplegia generated by 3D scanning. In preparation for shape deviation analysis, each position from the data was primarily adjusted in the $3 \mathrm{D}$ coordinate space by reflecting the position where the 3DP-pHRI was equipped to the wearable robot to determine the relative locations of the human body and the 3DP-pHRI model data. The shape deviation comparison function of Artec Studio 9 software was used for shape deviation analysis, calculated using the data of 10 human body and 3DP-pHRI model pairs completed using a matching process (Figure 13). Artec Studio 9 software can analyze the mean and standard deviation of shape deviations in the normal direction from two 3D data items with morphological similarity.

As a result of analyzing shape deviation, the average deviation of the trunk 3DP-pHRI showed a minimum value of $4.2 \mathrm{~mm}$ in sub2, and a maximum value of $9.32 \mathrm{~mm}$ in sub4. The average shape deviation of the shank 3DP-pHRI showed a minimum value of 1.9 $\mathrm{mm}$ in sub5, and a maximum value of $7.58 \mathrm{~mm}$ in sub10 (Table 12). The following three data sources were referenced for the tolerance range for evaluating the suitability of the analyzed shape deviation. In ISO 20685-1 (2018), the tolerance range of body depth is 5 $\mathrm{mm}$ [37], and the result report of the 2016 Korean human body size survey suggested the tolerance range of large width as 5.44-10.0 $\mathrm{mm}$ [38]. In the study of [24], the tolerance range of the human body cross section in the normal direction was suggested as $10 \mathrm{~mm}$. The tolerance range for conformance evaluation was set to $10 \mathrm{~mm}$ by additionally considering the error range of 5-10 mm suggested in the above reference materials and the allowable error range due to the characteristics of the open structure of 3DP-pHRI. 


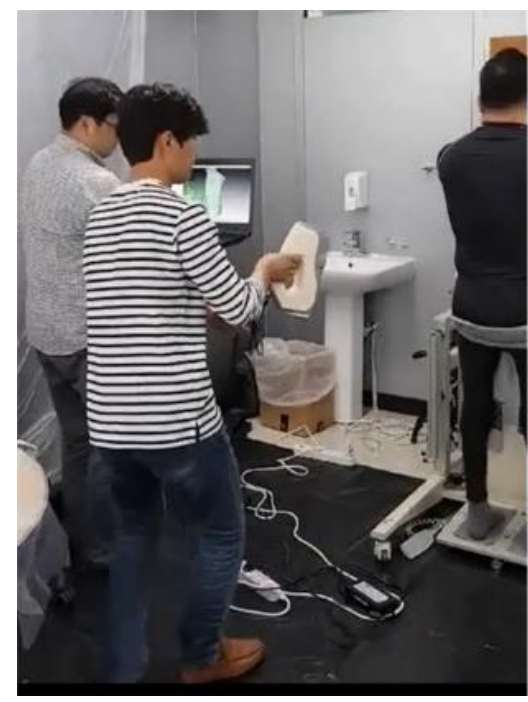

(a)

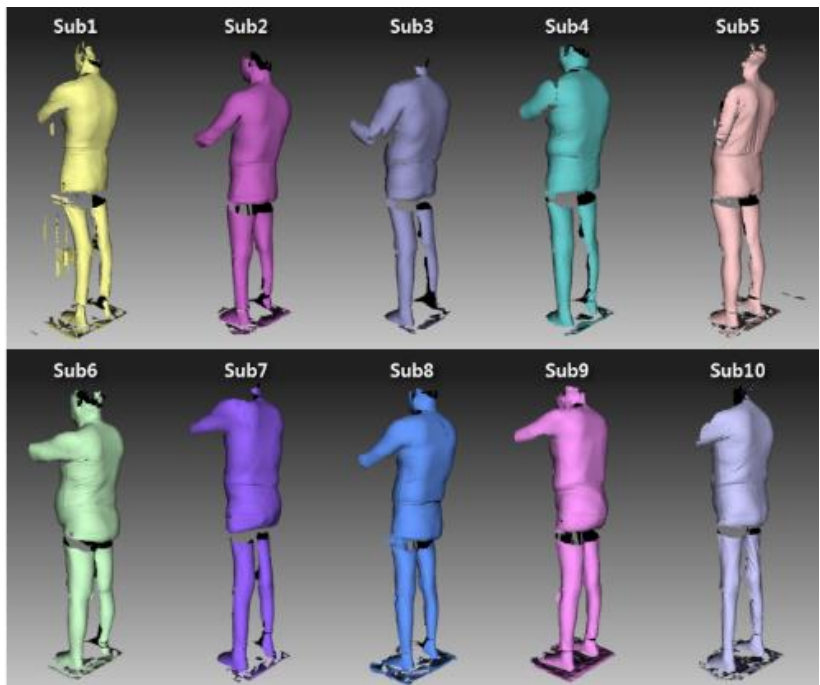

(b)

Figure 12. Secure human body shape data: (a) 3D scanning of human body shape and (b) 10 subjects' human body shape data.

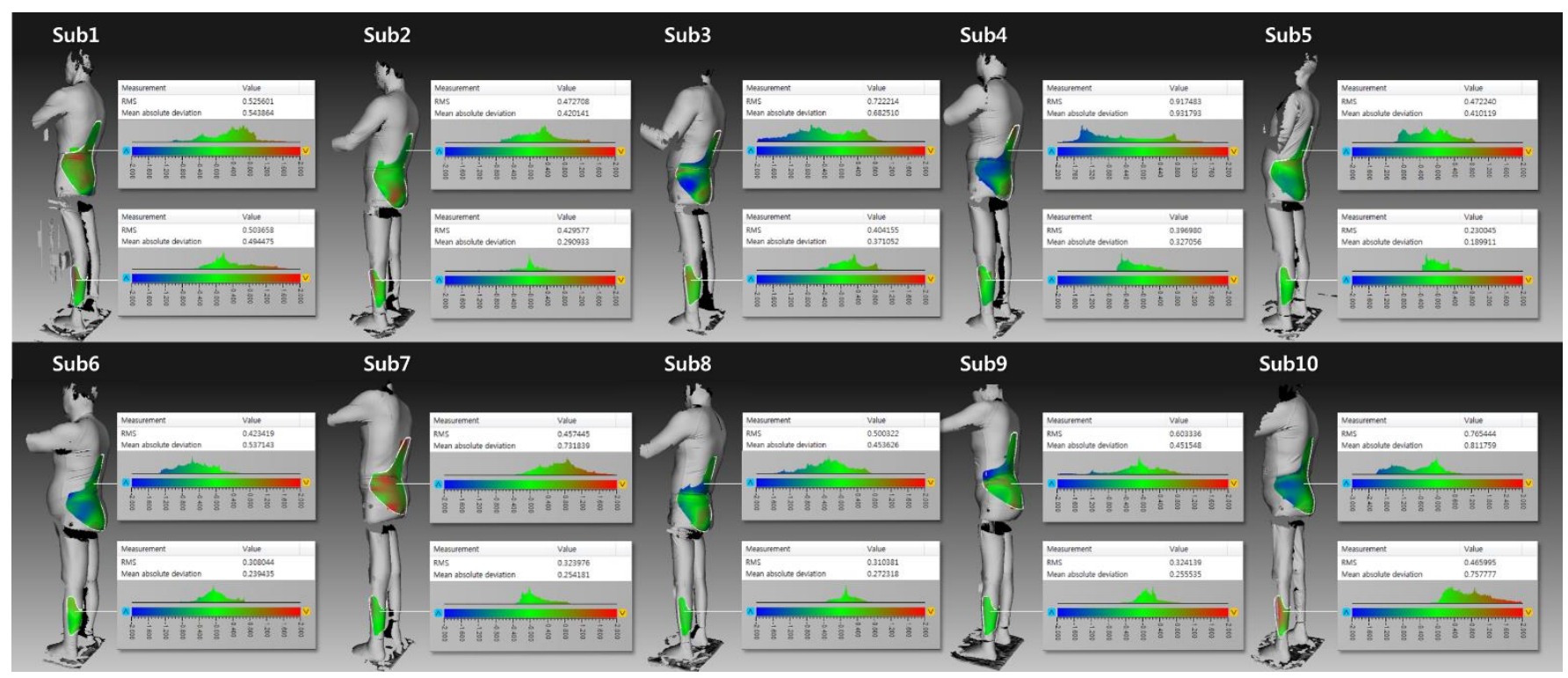

Figure 13. Results of evaluation by shape deviation analysis.

Table 12. Results of evaluation by shape deviation analysis (unit: $\mathrm{mm}$ ).

\begin{tabular}{|c|c|c|c|c|c|c|c|c|c|c|c|}
\hline & & Sub1 & Sub2 & Sub3 & Sub4 & Sub5 & Sub6 & Sub7 & Sub8 & Sub9 & Sub10 \\
\hline \multirow[t]{2}{*}{$\begin{array}{l}\text { Trunk } \\
\text { pHRI }\end{array}$} & Mean & 5.44 & 4.20 & 6.83 & 9.32 & 4.10 & 5.37 & 7.32 & 4.54 & 4.52 & 8.12 \\
\hline & SD & 5.26 & 4.73 & 7.22 & 9.17 & 4.72 & 4.23 & 4.57 & 5.00 & 6.03 & 7.65 \\
\hline \multirow[t]{2}{*}{$\begin{array}{l}\text { Shank } \\
\text { pHRI }\end{array}$} & Mean & 4.94 & 2.91 & 3.71 & 3.27 & 1.90 & 2.39 & 2.54 & 2.72 & 2.56 & 7.58 \\
\hline & SD & 5.04 & 4.30 & 4.04 & 3.97 & 2.30 & 3.08 & 3.24 & 3.10 & 3.24 & 4.66 \\
\hline
\end{tabular}

As a result of analyzing the average of the shape deviation in the normal direction for 10 human body 3DP-pHRI model pair data, all values were within $10 \mathrm{~mm}$ of the error 
range, confirming that the developed 3DP-pHRI based on the sizing system had conformity in shape and dimensions at an appropriate level.

\subsection{Discussion}

In this study, to libraryize 3DP-pHRI into various sizes and shapes, the method of subdividing the size section and the method of generating the average human model for each section was used. There are three methods for subdividing the size section: the grid method, the clustering method, and the optimization method. The grid method, which is most commonly used in the field of anthropometry, was used as the method for subdividing the size section. There are three methods of generating an average human body model: wireframe modeling, morphing modeling, and template model fitting transformation. The wireframe modeling, which is advantageous for averaging work that requires precision, was used as the average human body model generation method.

Products that have a size system such as clothing, shoes, gloves, and hats have a relatively low body fit sensitivity compared to wearable robots, and are manufactured using a mass production method. In the existing mass production method, the approach of developing all the size sections subdivided into 10 or more and the average human model for each section and applying them to the product is not suitable because production efficiency and economy are low. For this reason, in the case of applying the size system of a product line that requires conformity to the shape and dimensions of a human body, most of the approaches are to build a size system based on simple dimensions such as circumference, length, and width using a two-dimensional body size database. In most cases, only one to four limited average human models representing 25th-75th $\%$ are created and used as a supplement to product development.

However, since the wearable robot for the disabled with leg paralysis needs to be customized for pHRI so that an integrated connection between the human body and the robot can be made, a simple dimension-based size system applied to existing products and a wide range of median values are not suitable. In addition, 3DP-pHRI based on a size system using a limited number of average human body models cannot implement an appropriate body shape fit. Therefore, the size system of 3DP-pHRI should be subdivided into more detailed size sections and an average human model representing each subdivided section should be created and developed by referring to the shape of the human body surface of each created model. In this study, we developed 3DP-pHRI based on the size system that is subdivided into 18 size sections and libraryized by applying the most effective method among the methods used in the development of the existing size system. The value and importance of this study in that 3DP-pHRI based on a size system that can be mass customized with relatively little effort compared to the existing body shape customization of the wearable robot, which required significant effort, was developed and presented as a new alternative.

In this study, the pHRI of a wearable robot for rehabilitation training for people with paraplegia was studied. Patients with paraplegia due to SCI are divided into subacute and chronic phases based on 6 months after the onset of SCI. The subacute period is a period of intensive rehabilitation training. The subacute leg paralysis disorder has relatively less muscle contraction compared to the chronic leg paralysis disorder, and the muscle contraction is minimized depending on how actively rehabilitation training is performed during the subacute period. The wearable robot selected as the study target is the primary treatment target for subacute lower limb paralysis disorders, and the secondary treatment target for partial paralysis disorders such as subacute stroke and hemiplegia.

To develop the size system of the wearable robot's 3DP-pHRI targeting such users, a human body shape database should be used. However, there are various difficulties in securing a database of the human body shape of people with lower limb paralysis disorder. Since persons with lower limb paralysis cannot maintain standing state on their own, it must be erected using an artificial standing holding device. The 3D scan should be performed in a state where there is no physical interference factor that unnecessarily 
obstructs the human body shape. For these two reasons, securing a database of human body shape for people with leg paralysis disorder can be achieved through a very long-term project over several years.

In this study, a size system was developed using a database of normal persons due to the fact that it targets persons with subacute paralysis, which is the stage before sudden muscle contraction due to paralysis of the lower extremities, and the practical difficulty of securing the human body shape database of persons with paralysis of the lower extremities. In addition, the shape of the human body varies according to factors, such as country, adult-child, male-female, and so on. In this study, as the first step of the gradual study, the size system of 3DP-pHRI was developed using the human body shape database for Korean male adults.

A size system-based 3DP-pHRI was developed and proposed as a new alternative to realize the body shape-fit without the $3 \mathrm{D}$ scanning process and template remodeling process in the 3D printing body-fit of the wearable robot. In the existing template remodelingbased 3D printing body fit, the 3D scanning of the human body shape of the wearer is indispensable. It is very cumbersome and complicated because a specially designed standing posture maintenance device must be used to 3D scan the human body shape of a person with a paralysis disorder, and falls may occur in some cases due to insufficient safety management. 3D scanning data is additionally required for post-processing.

There is a variation in effort and time required according to the function of the 3D modeling program used in the remodeling process for 3D printing body shape fit based on template remodeling up to now. 3D modeling programs are divided into surfacebased modeling and solid-based modeling. For 3D printing production, solid-based modeling that completely fills the interior is most suitable. Existing solid-based modeling programs include polygon-based 3D animation-only modeling programs (e.g., Maya, 3D Max, Blender, etc.) and parametric solid modeling programs (e.g., SOLIDWORKS, CATIA, Proe, etc.) used for product design. Since 3DP-pHRI has an organic double-curve shape, it is difficult to use a parametric solid modeling program. Modeling program dedicated to 3D animation is advantageous for realizing an organic double-curved surface, and template remodeling can be implemented by utilizing some functions such as 'wrap geometry on a surface'. However, these programs have a disadvantage in that it is difficult to control dimensions such as the thickness or contour shape of a template based on parameters in the process of automatic deformation remodeling. As the shape complexity of the template increases, errors in automatic deformation remodeling increase.

Therefore, it is considered that 3D printing body fit based on template remodeling is not yet a feasible alternative due to the difficulty of the 3D scanning of the human body shape of the paralyzed person and the still incomplete automatic transformation remodeling process. In this respect, the size system-based 3DP-pHRI developed and proposed in this study is considered a more effective alternative compared to the existing template remodeling-based 3D printing body shape customization. However, research on the development of a dedicated platform that solves the difficulties of the 3D scanning process and that can fully implement the 3DP-pHRI remodeling process automatically is valuable as the ultimate future research goal.

\section{Conclusions}

This study is significant in that it provides a new 3DP pHRI based on the sizing system that does not require baseline remodeling for the customization of a wearable robot to fit a patient's body shape. The effectiveness of the innovation was verified by evaluating its conformity of shape and dimensions. The new 3DP pHRI was developed by segmenting size sections and creating an average human body model for each. The conformity of shape and dimensions was evaluated by visual observation and shape deviation analysis for 10 persons with paraplegia. The main research results are summarized as follows: 
(1) For size segmentation, 199 2D human body measurement data points were used as sample data. Using the grid method technique, 18 size sections meeting the coverage rate of $4-7 \%$ each, and a total coverage rate of $90.5 \%$ were defined.

(2) For the generation of the average human body model, 195 3D human body shape model data items were used as sample data, and a wireframe modeling technique based on body-section analysis was used to generate the average human body model for each of the 18 size sections.

(3) For system development, 18 trunk and nine shank sections were produced as sizing subsystems by referring to the surface shapes of the generated 18 average human body models.

(4) From the visual observation, a biased tendency of the shank-sizing system was identified. From the shape deviation analysis, all trunk and shank subsystems showed conformity of shape and dimensions at an appropriate level with a deviation range of $10 \mathrm{~mm}$.

The 3DP-pHRI system developed in this study can be applied to various wearable robot $\mathrm{pHRI}$ situations, and it is expected to contribute to a useful pHRI template library through follow-up research. In this study, a body shape database of people without disability was used to develop the sizing system, owing to the practical difficulty of obtaining such data from paraplegia patients. Owing to this limitation, the coverage rate bias mentioned above was identified. To overcome this problem, the application of structural parameter shape designs to induce variable controllability should be considered next. The follow-up studies will involve research on a structural parameter shape design to reinforce the shape control functions for the 3DP-pHRI based on the sizing system, as well as an empirical clinical evaluation research considering the coupling relationship with the robot.

Author Contributions: Conceptualization, C.-Y.K.; methodology, C.-Y.K. and J.-S.J.; software, C.Y.K.; validation, C.-Y.K., J.-S.J. and G.-S.K.; investigation, C.-Y.K.; data curation, C.-Y.K. and J.-S.J.; writing - original draft preparation, C.-Y.K. and J.-S.J.; writing—review and editing, J.-S.J. and G.-S.K.; visualization, C.-Y.K.; supervision, J.-S.J.; project administration, G.-S.K. All authors have read and agreed to the published version of the manuscript.

Funding: This research was supported by the Technology Innovation Program (or Industrial Strategic Technology Development Program (Project Number: 20003914)) and was funded by the Ministry of Trade, Industry and Energy (MOTIE, South Korea).

Institutional Review Board Statement: The study was conducted according to the guidelines of the Declaration of Helsinki, and approved by the Ethics Committee of Rehabilitation Engineering Research Institute (protocol code RERI-IRB-200318-2 and 18 March 2020).

Informed Consent Statement: Informed consent was obtained from all subjects involved in the study.

Conflicts of Interest: The authors declare no conflict of interest.

\section{References}

1. Young, A.J.; Ferris, D.P. State of the Art and Future Directions for Lower Limb Robotic Exoskeletons. IEEE Trans. Neur. Sys. Rehab. Eng. 2017, 25, 171-182. [CrossRef] [PubMed]

2. DeVivo, M.J. Epidemiology of traumatic spinal cord injury: Trends and future implications. Spinal Cord 2012, 50, 365-372. [CrossRef] [PubMed]

3. Choi, J.S.; Na, B.H.; Jeong, P.G.; Na, D.W.; Gong, K.C. WalkON Suit: A Wearable Robot for Complete paraplegics. J. Korea Robot. Soc. 2017, 12, 116-123. [CrossRef]

4. Nguyen, M.T.; Sankai, Y. Measurement method of interaction force between human and wearable assistive robot based on strain of contact part. In Proceedings of the SICE Annual Conference, Nagoya, Japan, 14-17 September 2013; pp. 401-406.

5. $\quad$ Farris, R.J.; Quintero, H.A.; Murray, S.A.; Ha, K.H.; Hartigan, C.; Goldfarb, M.A. Preliminary Assessment of Legged Mobility Provided by a Lower Limb Exoskeleton for Persons with Paraplegia. IEEE Trans. Neur. Sys. Rehab. Engin. 2014, 22, 482-490. [CrossRef] 
6. Contreras-Vidal, J.L.; Grossman, R.G. NeuroRex: A clinical neural interface roadmap for EEG-based brain machine interfaces to a lower body robotic exoskeleton. In Proceedings of the 35th Annual International Conference of the IEEE EMBS, Osaka, Japan, 3-7 July 2013; pp. 1579-1582.

7. Jung, J.Y.; Park, H.; Yang, H.D.; Chae, M. Brief Biomechanical Analysis on the walking of Spinal Cord Injury Patients with a Lower Limb Exoskeleton Robot. In Proceedings of the IEEE International Conference Rehabil Robot, Seattle, WA, USA, 24-26 June 2013; pp. 24-26.

8. Eom, R.I.; Lee, Y.J. Evaluation of Comfort in Wearing a Gait-Assistive Rehabilitation Robot. J. Korean Soc. Cloth. Textiles 2020, 44, 1107-1119. [CrossRef]

9. Kim, H.S.; Koo, D.S.; Nam, Y.J.; Cho, K.J.; Kim, S. Research on Technology Status and Development Direction of Wearable Robot. Fash. Textile Res. J. 2019, 21, 640-655. [CrossRef]

10. del Carmen Sanchez-Villamañan, M.; Gonzalez-Vargas, J.; Torricelli, D.; Moreno, J.C.; Pons, J.L. Compliant lower limb exoskeletons: A comprehensive review on mechanical design principles. J. Neuroengin. Rehab. 2019, 16, 55. [CrossRef]

11. De Rossi, S.M.M.; Vitiello, N.; Lenzi, T.; Ronsse, R.; Koopman, B.; Persichetti, A.; Vecchi, F.; Ijspeert, A.J.; Van der Kooij, H.; Carrozza, M.C. Sensing pressure distribution on a lower-limb exoskeleton physical human-machine interface. Sensors 2011, 11, 207-227. [CrossRef]

12. Langlois, K.; Moltedo, M.; Bacek, T.; Rodriguez-Guerrero, C.; Vanderborght, B.; Lefeber, D. Design and development of customized physical interfaces to reduce relative motion between the user and a powered ankle foot exoskeleton. In Proceedings of the 7th IEEE International Conference on Biomedical Robotics and Biomechatronics (Biorob), Enschede, The Netherlands, 26-29 August 2018; pp. 1083-1088.

13. Cherry, M.S.; Kota, S.; Young, A.; Ferris, D.P. Running with an Elastic Lower Limb Exoskeleton. J. Appl. Biomech. 2016, 32, $269-277$. [CrossRef] [PubMed]

14. Jang, I.H.; Lee, D.Y.; Jeong, J.Y.; Lee, D.W.; Lee, H.G.; Park, H.S. Development of Gait Assisting Rehabilitation Robot for SCI (Spinal Cord Injury) Patient. J. Ins. Contr. Robot. Sys. 2010, 16, 860-865. [CrossRef]

15. Li, N.; Yan, L.; Qian, H.; Wu, H.; Wu, J.; Men, S. Review on lower extremity exoskeleton robot. Open Autom. Ctrl. Sys. J. 2015, 7, 441-453.

16. Rathore, A.; Wilcox, M.; Ramirez, D.Z.M.; Loureiro, R.; Carlson, T. Quantifying the human-robot interaction forces between a lower limb exoskeleton and healthy users. In Proceedings of the 38th Annual International Conference of the IEEE Engineering in Medicine and Biology Society (EMBC), Orlando, FL, USA, 16-20 August 2016; pp. 586-589.

17. Tamez-Duque, J.; Cobian-Ugalde, R.; Kilicarslan, A.; Venkatakrishnan, A.; Soto, R.; Contreras-Vidal, J.L. Real-time strap pressure sensor system for powered exoskeletons. Sensors 2015, 15, 4550-4563. [CrossRef] [PubMed]

18. Veneman, J.F.; Kruidhof, R.; Hekman, E.E.G.; Ekkelenkamp, R.; Van Asseldonk, E.H.F. Design and evaluation of the LOPES exoskeleton robot for interactive gait rehabilitation. IEEE Trans. Neur. Sys. Rehab. Eng. 2007, 15, 379-386. [CrossRef] [PubMed]

19. Walsh, C.J.; Endo, K.; Herr, H. A quasi-passive leg exoskeleton for load-carrying augmentation. I. J. Humanoid Robot 2007, 4 , 487-506. [CrossRef]

20. Pons, J.L. Rehabilitation Exoskeletal Robotics. IEEE Eng. Med. Biol. Mag. 2010, 29, 57-63. [CrossRef]

21. Beil, J.; Perner, G.; Asfour, T. Design and Control of the Lower Limb Exoskeleton KIT-EXO-1. In Proceedings of the IEEE International Conference on Rehabilitation Robotics (ICORR), Singapore (SingCambridgeapore), 11-14 August 2015; pp. 119-124. [CrossRef]

22. Junius, K.; Brackx, B.; Grosu, V.; Cuypers, H.; Geeroms, J.; Moltedo, M.; Vanderborght, B.; Lefeber, D. Mechatronic Design of a Sit-to-Stance Exoskeleton. In Proceedings of the 5th IEEE RAS \& EMBS International Conference on Biomedical Robotics and Biomechatronics (BioRob), Sao Paulo, Brazil, 12-15 August 2014; pp. 945-950. [CrossRef]

23. Schrade, S.O.; Dätwyler, K.; Stücheli, M.; Studer, K.; Türk, D.A.; Meboldt, M.; Gassert, R.; Lambercy, O. Development of VariLeg, an exoskeleton with variable stiffness actuation: First results and user evaluation from the CYBATHLON. J. Neuroeng. Rehab. 2018, 15, 18. [CrossRef]

24. Nam, Y.J.; Choi, K.M.; Park, S.M. 3D Human Body Modeling Using 3D Data. Fiber Techn. Indust. 2006, 10, $251-258$.

25. Shin, J.Y.; Choi, Y.R.; Nam, Y.J. Development of a Representative Model for Different Body Shapes of 18-24 Aged Women-An Application of a 3D Morphing Technique. Fash. Textile Res. J. 2011, 13, 590-599. [CrossRef]

26. Park, S.M.; Nam, Y.J.; Choi, K.M. A Study of 3D Virtual Fitting Model of Men's Lower Bodies in Forties by Morphing Technique. J. Korean Soc. Cloth. Textiles 2007, 31, 463-474. [CrossRef]

27. Lee, B.; Jung, K.; You, H. Development of a Distributed Representative Human Model Generation and Analysis System for Multiple-Size Product Design. J. Ergon. Soc. Korea 2011, 30, 683-688. [CrossRef]

28. Jeon, E.J.; Park, S.K.; Yu, H.C.; Kim, H.E. Development of a Sizing System and a Draping Pattern for Hip Protector based on 3D Data Analysis of Korean Older Women. Fash. Textile Res. J. 2016, 18, 120-129. [CrossRef]

29. Choi, S.I. Studies on Representative Body Sizes and 3D Body Scan Data of Korean Adolescents. JKAIS 2016, 17, $227-232$.

30. Jeon, S.H.; Seo, H.W. Calculation of the Average 3D Model for Koreans Using the 3D Scan Model. In Proceedings of the Society of Computational Design and Engineering Conference, Pyeongchang, Korea, 4-6 February 2009; pp. 550-553.

31. Yoon, D.W.; Heo, N.B.; Ko, H.S. Landmark Extraction for 3D Human Body Scan Data Using Markerless Matching. In Proceedings of the HCI, San Diego, CA, USA, 19-24 July 2009; pp. 163-167. 
32. Jang, T.H.; Paek, S.Y.; Lee, G.W. Synthesis of Human Body Shape for Given Body Sizes using 3D Body Scan Data. Korean J. Comput. Des. Engin. 2009, 14, 364-373.

33. Jung, K.; Kwon, O.; You, H. Evaluation of the multivariate accommodation performance of the grid method. Appl. Ergon. 2010, 42, 156-161. [CrossRef] [PubMed]

34. Robinette, K.M.; Annis, J.F. A Nine-Size System for Chemical Defense Gloves (Technical Report AAMRL-TR-86-029); Wright-Patterson Air Force Base: Greene County, OH, USA, 1986.

35. Laing, R.M.; Holland, E.J.; Niven, B.E. Development of sizing systems for protective clothing for the adult male. Ergonomics 1999, 42, 1249-1257. [CrossRef] [PubMed]

36. McCulloch, C.E.; Paal, B.; Ashdown, S.P. An optimization approach to apparel sizing. J. Oper. Res. Soc. 1998, 49, 492-499. [CrossRef]

37. Korean human body size survey. Regular Statistical Quality Diagnosis Result Report; Statistical Office: Daejeon, Korea, 2016.

38. ISO 20685-1:2018. 3-D Scanning Methodologies for Internationally Compatible Anthropometric Databases; ISO: Geneva, Switzerland, 2018. 